This PDF is a selection from an out-of-print volume from the National Bureau of Economic Research

Volume Title: Medical Care Output and Productivity

Volume Author/Editor: David M. Cutler and Ernst R. Berndt, editors

Volume Publisher: University of Chicago Press

Volume ISBN: 0-226-13226-9

Volume URL: http://www.nber.org/books/cutl01-1

Publication Date: January 2001

Chapter Title: Health Care Output and Prices in the Producer Price Index

Chapter Author: Dennis Fixler, Mitchell Ginsburg

Chapter URL: http://www.nber.org/chapters/c7631

Chapter pages in book: (p. 221 - 270) 


\title{
Health Care Output and Prices in the Producer Price Index
}

\author{
Dennis Fixler and Mitchell Ginsburg
}

\subsection{Introduction}

In recent years considerable attention has been directed to the importance of the health care sector to the economy. As there is no formal definition of the sector, its definition is arbitrary. One naturally thinks of hospitals, physicians, and pharmaceuticals as part of the sector, but one could also legitimately include the manufacturers of hospital equipment, bandages, and so on. The sector, however, is generally defined to focus on the treatment of ailments or the relief of pain and suffering, and this is the perspective adopted by the Bureau of Labor Statistics (BLS). Within the context of the Producer Price Index (PPI), the health care sector is viewed as containing the following service and manufacturing industries (by Standard Industrial Classification [SIC]): hospital and related services (SIC 806), physicians (SIC 8011), medical labs (SIC 8071), nursing homes (SIC 8053), drugs (SIC 283), and home health care (SIC 8082).

The industrial classification of the relevant industries will change shortly with the implementation of the North American Industrial Classification System (NAICS) agreed to in $1996 .{ }^{1}$ This system will allow the U.S. prod-

Dennis Fixler is research economist and chief of the Division of Price and Index Number Research at the Bureau of Labor Statistics. Mitchell Ginsburg is an international economist in the Applied Economics Division of the United States International Trade Commission.

The authors thank Greg Kelly, Teresa McKeivier, Bonnie Murphy, John Nelson, William Page, and Roslyn Swick for their assistance. This paper represents the views of the authors alone and does not represent either BLS or USITC policy or the views of other staff members. The paper was completed while Ginsburg was an economist in the Producer Price Index Program in the Office of Prices and Living Conditions.

Copyright is not claimed for this chapter.

1. See Federal Register, 9 April 1997, for a description of NAICS. 
uct codes to be mapped into a system that is similar to the ones used in other countries. Many of the changes are minor and concern small aspects of the above SIC categories; for example, transportation services supplied by ambulances are in the NAICS Health Care and Social Assistance sector (sector 62) but under the SIC system they were in the transportation sector.

To economize on the explanation of index number construction and the associated problems, the focus of this paper is on the PPI indexes for hospitals, physicians, and drugs. The indexes for medical labs, nursing homes, and home health care will also be briefly described. Before discussing the indexes, a brief description of the conceptual framework underlying the Producer Price Index is presented.

\subsection{Conceptual Framework}

The PPI conceptual framework relies on the theory of output price indexes as formulated by Archibald (1977), Diewert (1983), and Fisher and Shell (1972). In this framework firms are viewed as competitive price takers that choose output quantities to maximize revenue for given technology and inputs. The application of the framework to the health care sector is complicated by the prominence of nonprofit firms, especially hospitals, and the fact that the outputs are not standardized. ${ }^{2}$ Each of these aspects is discussed below and we give a brief presentation of output price index number theory.

\subsubsection{Aggregation across Firm Types}

Given the variety of organizational types in the health care sector, an issue from the perspective of index number construction is whether it is legitimate to combine the prices collected from the various types of firms. To do so requires some assumptions: Output prices are exogenous, firms use the output prices to make their production decisions, and firms are efficient in the sense that they operate on their production and cost frontiers.

\section{Price Exogeneity}

Price exogeneity is usually not an issue of concern because of the presumption of a competitive industry. However, because of the prominence of nonprofit firms in the health sector, principally hospitals, it is necessary to consider whether such firms can be incorporated into the PPI framework. Considerable attention has been paid in the hospital literature to the behavioral differences between profit and nonprofit organizational types. ${ }^{3}$ Nevertheless it is generally agreed that there is some form of competition

2. In the 1992 Census of Services there were about 3,800 general medical and surgical hospitals in SIC 8062. About 84 percent were exempt from federal income tax and therefore may be considered nonprofit.

3. See for example, Newhouse (1970), Weisbrod (1975), and Jacobs (1974). 
between hospitals but that it may manifest itself more in terms of nonprice rather than price competition. Noether (1988) provides evidence that price competition plays an important role in the hospital industry.

Industry structure, however, is not the only factor affecting price exogeneity. One also has to consider the implications of the fact that most treatments are paid for by third parties, principally insurers (including government through Medicare and Medicaid). These payers negotiate with providers the price that they will pay for services, and recently they have begun to specify the content of treatments, as in the case of managed care ${ }^{4}$ One could argue that, given the increasing importance of these payers, especially Medicare, there is an increased focus on price competition. Further, because these negotiations cover all the treatments that a hospital may provide, one may view the price as being exogenous for a specific transaction between a hospital and a patient covered by a third-party payer.

\section{Organization Decision Making}

There are two dimensions to the impact of organizational type on output decisions. First, the difference in objective may cause nonprofit firms to produce output bundles that are systematically different from those produced by for-profit firms. Second, the output decisions of nonprofits may differ from those of for-profit firms because they may receive charitable contributions, which can reduce the need to pay for inputs through revenue generation, and because they face a zero corporate tax rate.

Evidence on the actual impact of these differences is slim. Needham (1978), for one, argues that these two organizational forms are more similar than different in their behavior. In fact, if one viewed nonprofit firms as using their charitable contributions and tax advantage to reduce input costs in a lump sum fashion and not to charge lower (or subsidized) output prices, then these influences would become unimportant. A related issue is that of efficiency of production. In order to compare the impact of relative price changes on the output decisions of the two firm types, one must assume that they are equally efficient. This assumption has empirical support in the sense that evidence suggests that the two firm types are equally inefficient. ${ }^{5}$

4. As will be discussed below, a change in the character of treatment is one of the main issues in accounting for change in quality.

5. Studies of hospital efficiency have found that on average both types of hospitals are inefficient; that is, they do not use the minimum quantity of inputs to produce a given level of output. See for example Register and Bruning (1987). A natural question arises about the implications for output quality of efforts to improve efficiency. One can envision degradation of output quality arising from such effort. For example, suppose that a hospital reduced the amount of time a nurse is to spend with a patient and thereby reduces the "attentiveness" aspect of care. The same level of output could be achieved with a smaller number of nurses and such a reduction may make the hospital more efficient. As will be explained later, the PPI looks at the nurse-to-patient ratio as one indicator of quality of service. Since that ratio declines in this example, the PPI would treat this change as a change in the quality of service. 
In the context of the theory of the firm, the organizational type can be viewed as a parameter in the production function that affects the transformation of inputs into outputs. Changes in the organizational framework can thus be viewed as shifting the frontier or changing its slope at various points. Viewed this way the objective of either firm type would be to maximize revenue subject to the corresponding production frontier. These points are elaborated in section 6.2.4 after a discussion of the definition of price and outputs.

\subsubsection{Output and Price}

In theory, the output of the firm is an easily identifiable product/service whose price is well defined. The price should represent the transaction price. Also, to accurately gauge the movement of price over time, one should be able to identify changes in product quality and set the corresponding money value. Because achieving these measurement objectives is more difficult in the hospital and physician industries than in the drug industry, where at least the measurement of output is straightforward, our discussion focuses on hospitals and physicians.

Hospitals and physicians treat illness, and therefore the object of pricing for both is a treatment. Attaining this objective is far more difficult than it may appear on first examination. One reason is that for many treatments there is no obvious endpoint. For example, if an individual enters a hospital for chest pains, he may not only be treated for that particular episode but he may also be required to return for a series of follow-up examinations. The same problem exists for visits to a physician's office; it may take several consultations after a first visit for a problem before the treatment is completed. Varieties of physician skill and the uncertainty surrounding the probabilities of success for different treatments also determine the treatment package.

Another impediment arises from the fact that the PPI must define treatments within industry boundaries. Thus, if a treatment path requires a hospital stay and a series of visits to a physician, these will be treated separately. This constraint also affects the measurement of substitution among treatments; if pharmaceutical products were substituted for either physician or hospital services then the substitution would not be captured.

To overcome some of the above complications, the PPI program defines a treatment within the context of a given bill for a single encounter between a patient and a hospital or a patient and a physician. The bill specifies the set of procedures supplied to a given patient, and it also allows the

6. See Frank, Berndt, and Busch (chap. 12 in this volume) for a demonstration of the importance of bundling physician services with pharmaceuticals in measuring the price change for the treatment of depression. 
BLS to monitor the charges acceptable to different payers. But this solution is limited by the fact that patients are not homogeneous, so that a bill will vary by the severity of the condition in the patient. ${ }^{7}$ In addition the reliance on a bill also implies that one must distinguish between billed charges and the actual reimbursement to the hospital, which would represent the transaction price.

\subsubsection{New Goods and Change in Quality}

The health care sector is one of the most dynamic sectors in the economy. There is a steady stream of new treatments, equipment, drugs, and so on. Indeed society pays an enormous amount of attention to innovations in the health field. For index number makers such dynamism presents major hurdles. First, for the continued pricing of specific goods, constancy of quality is necessary so that the measured price change is meaningful. Second, the introduction of new goods creates the problem of how to incorporate new products into the index in the best way. In the health care sector there is the additional problem of handling the substitution of one type of treatment for another. A new technique for a treatment may transform an inpatient hospital treatment into an outpatient treatment. Also, the introduction of a new drug may induce physicians to substitute drug therapy for hospital treatments-in the early 1990s the annual cost of drug therapy for ulcers amounted to $\$ 900$ compared to the $\$ 28,000$ for surgery (PhRMA 1997).

Because the methods used to adjust an index for new goods are different from those used for changes in the quality of existing goods, it is important to distinguish between the two. In principle, new goods could be designated as goods that did not exist previously or as major changes in an existing product's quality that render it no longer comparable to the previous version. Minor product changes would then be ones for which some adjustment can be made to the price of the new version that would still permit a valid comparison with the previous version. An example of the latter would be changes in the packaging of drug product, and an example of the former would be the replacement of surgery for kidney stones by lithrotripsy. ${ }^{8}$

The implementation of such adjustments, however, is often difficult because of the absence of information surrounding the efficacy and diffusion

7. An alternative scheme for the pricing of treatments would be to select a hospital and a payer and then sample among the bills for a treatment of an illness submitted to that payer. In this way one may capture the importance of patient characteristics and (perhaps more importantly) the fact there is a distribution of prices for a treatment within a hospital. Another scheme would be simply to take the average of all bills within a hospital for a given treatment, paid by a specific payer. Such a plan would impose substantial reporting requirements and complicate the measurement of price for a treatment in that there is not a specific bundle of attributes from which changes in quality could be ascertained.

8. Lithrotripsy is the use of ultrasound to crush stones, usually in the bladder or kidney. 
of new techniques, equipment, and drugs. In the market for most goods and services the success of product and process innovations is determined relatively quickly by the interaction of supply and demand. In contrast, the success of innovations in the health care sector is determined by lengthy studies of efficacy. To illustrate some of the questions that arise, consider the introduction of new techniques and new products for hip replacement. At what point should these be incorporated into the price index - at introduction or when some threshold level of usage has been surpassed? If the changes in hip replacement techniques are relatively minor, should a change in the quality of hip replacements be automatically registered or should there be some evidence of efficacy? If a quality change is registered and at some future date a consensus deems the technique detrimental, should the past indexes be revised?

The handling of the types of product changes described above is most often accomplished by examining the characteristics of the product and ascertaining whether the new bundle of characteristics is a major or minor change from the product's existing product bundle. The identification of the set of relevant characteristics is not straightforward. For example in the case of measuring the quality of hospital treatments, it is not clear whether attention should be paid to process (hospital staff, facilities) or outcome (the efficacy of the treatment).$^{9}$ Nevertheless, in the theory outlined below there is a reliance on the incorporation of product characteristics and in the effectiveness of what is referred to as the hedonic approach. $^{10}$

Perhaps one of the more complicating features of quality measurement is the fact that the payer also determines the treatment package and thereby can affect measured quality change. Consider two firms A and B and their coverage for the treatment of kidney stones. Suppose firm A pays $x$ dollars for the surgical treatment of kidney stones while B pays $y$ dollars for the use of lithrotripsy. Also suppose that at time $t$ the PPI sampling procedure of hospitals selects the kidney stone treatment covered by A. In principle, the sampling procedure should select some lithrotripsy treatments at different hospitals. The sticky issue of quality change arises if at $t+n$ firm A decides to switch its coverage to lithrotripsy. More specifically the question is whether the switch is one for which an adjustment can be

9. There has been some discussion about the relative merits of focusing on process or outcomes in assessing the quality of medical care. See for example the 20 November 1996 exchange of letters in the Journal of the American Medical Association about assessing quality of care. How to measure medical outcomes has also received considerable attention. Aside from straightforward measures such as mortality, much research has been undertaken to develop the concept of quality-adjusted life years and its derivatives such as costeffectiveness.

10. In the hedonic approach, typically the price of a product is regressed on product characteristics thought to affect price. The use of product characteristics in such a way is not without limitations. A discussion of the issues is presented in Pakes (1997). 
made or one that is noncomparable and should be treated as a different treatment.

\subsubsection{Theory of Output Price Indexes}

Consider a firm that transforms the input vector $v$ into the output vector $x$. The difference between the quantity-quality decisions of a for-profit and a nonprofit hospital can be viewed as affecting the way inputs are transformed into outputs. Let $c$ denote the firm type characteristic. A firm's production relationship can be characterized as

$$
F(v, c)=[x \mid(x, v, c) \in T]
$$

for given $v$ and $c$ and where $T$ is the technology set and denotes the $v$ inputs that can produce $x . F(v, c)$ is thus the set of feasible outputs for a given quantity of inputs conditioned by the hospital type.

The conceptual output price index is based on a firm's revenue function. Define the revenue function for a hospital as

$$
R(p, v, c)=\max _{x}[p x \mid x \in F(v, c)]
$$

The conceptual output price index between periods 0 and 1 is given by

$$
I\left(p^{0}, p^{1}, v^{r}, c^{r}\right)=\frac{R^{r}\left(p^{1}, v^{r}, c^{r}\right)}{R^{r}\left(p^{0}, v^{r}, c^{r}\right)}
$$

where $r$ denotes the reference period for the determination of the relevant technology set, input vector, and hospital characteristic. If $r$ is equal to 0 , then the index takes a Laspeyres perspective, and if $r$ is equal to 1 , then the index takes a Paasche perspective. ${ }^{11}$ The index $I(\cdot)$ is for a specific hospital of type $c$. We can aggregate these indexes to obtain an industry index, conditioned on the various organizational forms. Because the above framework applies to the inclusion of any product characteristic, it forms the conceptual foundation for our hedonic approach to quality adjustment. ${ }^{12}$

Index number makers of course have to come up with a way of computing the index in equation (1). Most statistical agencies do so by setting $r$ equal to $t-1$, ignoring $c$ (competitive firms are assumed), and using the Laspeyres index formula to obtain

(2) $\quad I_{L}\left(p^{t}, p^{t-1}, v^{t-1}\right)=\frac{p^{t} \cdot x^{i-1}}{p^{t-1} \cdot x^{t-1}}=\sum_{i} \frac{p_{i}^{t}}{p_{i}^{t-1}} \times s_{i}^{t-1} ; s_{i}^{t-1}=\frac{p_{i}^{t-1} x_{i}^{t-1}}{\sum_{i} p_{i}^{t-1} x_{i}^{t-1}}$.

11. In a Laspeyres perspective, one answers the question "How much does a collection of goods selected in the past cost today?" In a Paasche perspective, one answers the question "How much would a collection of goods selected today cost in some past period?"

12. For an application of this framework to the construction of superlative index numbers see Fixler and Zieschang (1992). 
The second equality in the second row shows the Laspeyres index as a revenue share weighted average of the price relative to the ratio of prices in each period. Observe that by definition the denominator in equation (2) is equal to the denominator in equation (1). The numerator in equation (2) is an unobservable lower bound estimate of the numerator in equation (1). It follows that the index in equation (2) is a lower bound to the index in equation (1) and therefore potentially understates the true level of inflation. This potential measurement error is a well-known property of the Laspeyres index number formula. Though there has been much work on the relative merits of various index number formulas, here the concern is with difficult measurement problems that would arise regardless of the index number formula selected. Consequently, the discussion will be in terms of the commonly used Laspeyres formula.

\subsection{Hospital Price Indexes}

\subsubsection{Industry Definition}

The hospital price index was first published in 1993 and the underlying development work began in the late 1980s. The current index is based on research launched and data collected in 1989 and will soon be updated as described below. ${ }^{13}$

In the 1987 SIC Manual, hospitals in SIC 806 are defined as those establishments primarily engaged in the provision of diagnostic services, extensive medical treatment including surgical services, continuous nursing services, and other health care related services. These establishments have an organized medical staff, inpatient beds, and equipment and facilities for providing complete health care. Hospitals are placed into categories: general medical and surgical (SIC 8062), psychiatric (SIC 8063), and specialty, excluding psychiatric (SIC 8069). Not included in this industry are veterinary services (SIC 074), convalescent homes with extended care (SIC 8051 ), and associations or groups which limit their services to the provisions of insurance coverage against hospitalization or medical costs (SIC major group 63). The SIC definitions do not distinguish between hospitals in terms of ownership and control.

General medical and surgical hospitals are defined as providers of general medical, surgical, and other hospital-related services. These establishments provide services that range from room, board, and nursing services to the provision of highly specialized diagnostic and therapeutic services. Outpatient departments operated by hospitals are also included. Psychiat-

13. Information provided in the following discussion of the hospital, physician, medical labs, nursing homes, and home health care indexes is from internal BLS documents if a source is not specifically cited. 
ric hospitals are establishments that provide diagnostic medical services and inpatient treatment for the mentally ill. Establishments so classified include mental hospitals and psychiatric hospitals, including children's psychiatric hospitals. In general, all hospitals with a majority of revenues from psychiatric services are classified under SIC 8063. Hospitals or institutions for the mentally retarded are not included (SIC 8051). Specialty hospitals are defined as establishments providing diagnostic services, treatment, and other hospital services for patients with specified types of illnesses, except mental. Establishments included in this classification are children's hospitals; women's hospitals; orthopedic hospitals; rehabilitation hospitals; cancer hospitals; eye, ear, nose, and throat hospitals; tuberculosis and other respiratory illness hospitals; alcoholism and other chemical dependency hospitals, and other specialty hospitals, except psychiatric.

With the implementation of NAICS, minor changes will occur to the hospital industry definitions. Under NAICS, general medical and surgical hospitals (NAICS 62211) will also include children's hospitals, which under the SIC system are in the specialty hospital industry. Psychiatric and substance abuse hospitals will be combined under the NAICS classification code 62221 .

\subsubsection{Sample Unit Information}

The sample frame (master list) used for the selection of hospitals was drawn from the 1989 American Hospital Association Guide to the Health Care Field (AHA Guide). ${ }^{14}$ Federal hospitals such as military, Veterans Administration, and National Institutes of Health were eliminated because there is no measurable economic transaction between patient and hospital. Only hospitals with six or more beds could potentially be included in the index.

The sample frame was stratified into homogenous categories according to an urban-rural designation and the number of beds at the hospital. The stratification consisted of four categories: small rural (no more than 60 beds), large rural (greater than 60 beds), small urban (no more than 250 beds), and large urban (greater than 250 beds). This stratification was based on a study of the frequency distribution of treatments (Catron and Murphy 1996, 31).

The selection of a particular hospital was based on a probability proportionate to size sampling strategy. The size variable was the number of ad-

14. The AHA Guide was used as the frame instead of the Unemployment Insurance File (UI File), the typical PPI sampling universe, because the AHA Guide provided several potential size measures: employment, revenue, expenses, number of beds, and number of admissions. In addition, it provided details on each hospital's medical facilities, ownership, type of service rendered, and key contacts. The Unemployment File provided only establishment name, address, and employment. 
missions, based on 1989 data. ${ }^{15}$ In the cases where admission figures were not available from the American Hospital Association Annual Survey, the admissions figure was imputed using the number of annual admissions per bed and total number of beds.

For SIC 8062, 358 general hospitals were selected, which represents about 89 percent of all hospital revenue in 1989. According to the AHA Guide, over 83 percent of the 6,356 registered hospitals in $1989(5,316)$ were general hospitals. ${ }^{16}$ The number of beds and the hospital's urban/ rural designation determined the number of quotes assigned to the hospital. ${ }^{17}$ The number of quotes assigned ranged from six to ten. Medicare inpatient price data is obtained directly by PPI because it is available from the Federal Register.

The AHA Guide also revealed that nearly 10 percent of the registered hospitals were psychiatric hospitals. For SIC 8063,75 psychiatric hospitals were selected for inclusion in the index, representing 5.8 percent of 1989 hospital revenue. Fifty-five of the hospitals were private and the remaining twenty were state or county. Each sample unit was assigned six price quotes for collection. The Washington BLS office used AHA revenue data to determine the number of inpatient (Medicare and non-Medicare), outpatient, and miscellaneous quotes to be collected for each hospital. For the state/county hospitals, the last six transactions were selected. Four of the state/county hospitals were to provide price quotes for their last five treatments and one price quote for miscellaneous receipts.

According to the AHA Guide, approximately 7 percent of the registered hospitals were specialty hospitals. For SIC 8069,125 specialty hospitals were selected for inclusion in the index, representing approximately 5 percent of hospital revenue. For the fifty-three selected children's and women's hospitals, between six and ten price quotes were assigned for collection. For the seventy-two other specialty hospitals, six quotes were assigned. The Washington BLS office randomly determined the number of inpatient, outpatient, and miscellaneous quotes to be collected for each hospital.

15. Prior to selecting admissions as the size measure, regression analysis was performed to determine which variable provided in the AHA Guide frame provided the best correlation to size. Other variables that were candidates for measures of size were total expenses, payroll expenses, full-time equivalent employees, average daily census, and number of beds.

16. The AHA Guide does not rely on the SIC definitions to categorize hospitals - the AHA count of hospitals is based on hospital registrations that meet ten requirements. Accordingly, the number of hospitals in the AHA Guide can be different from the number obtained using the SIC definition.

17. The PPI sampling procedure begins with the drawing of two independent samples (half samples). The number of quotes assigned to a sample unit depends on the number of half samples it was selected in. The numbers vary with industry but one of the common allocations is four, six, and eight. With this allocation a sample unit selected in one half sample is assigned four quotes, a sample unit selected in both half samples is assigned six quotes, and a sample unit that was certainty-selected is assigned eight quotes. Because the independent samples are proportionate to size, the larger the sample unit, the greater chance it will be certainty-selected or selected in both half samples and assigned a higher number of quotes. 
The hospital sample size decreased as the index aged. As of July 1997, there were approximately 209 establishments with 1,602 quotes in the general hospital index, thirty-nine establishments with 209 quotes for the psychiatric hospital index, and seventy-two establishments with 491 quotes in the specialty hospital index. Two reasons can explain most of the erosion in the sample. First, many hospitals have changed billing systems and the older bills that were being used for repricing are no longer in the hospital billing system. When this occurs, the reporter cannot easily complete the repricing form. ${ }^{18}$ Further, many reporters did not wish to provide new patients as substitutes and then canceled their participation. Second, reporters changed their minds about participating in the index. As reporters receive no compensation for their time and effort, it is not uncommon that they end their participation in the later years of an index. This phenomenon has affected the hospital index as well as the other health care indexes.

\subsubsection{Output and Price Determination}

Hospitals are viewed as providing treatments, each of which is a bundle consisting of medical procedures, room, medical supplies, drugs, and ancillary services. Though there are several schemes that could be used to bundle hospital services, the PPI uses the Diagnostic Related Groups (DRG) formulated by the Health Care Financing Administration (HCFA) to price services paid by Medicare. Each DRG consists of a bundle of diagnostic and procedural codes that are in turn based on the International Classification of Diseases, 9th revision (ICD-9). DRGs are also grouped into more general categories called major diagnostic categories (MDC). The various MDCs represent the different product categories for the hospital industry. Examples of MDCs are diseases and disorders of the nervous system; pregnancy, childbirth, and the puerperium; diseases and disorders of the eye; and diseases and disorders of the respiratory system. These product categories were used for the publication structure for general and surgical hospitals (SIC 8062); that is, the component service products of the index. The publication structure for specialty hospitals except psychiatric was based on the different specialty hospitals. For psychiatric hospitals, the publication structure was based on inpatient/outpatient status and whether the hospital was private or state/county. Appendix table 6A.1 provides the publication structure as well as recent index levels.

The process of data collection begins with the visit by a BLS field representative to the sample unit. Usually, at this visit the field representative determined, through a process called disaggregation, the item that will be priced. In the case of hospitals, however, the Washington BLS office selected the service to be priced in order to obtain a manageable number of

18. As explained later, the PPI program collects price information via a monthly repricing form mailed to reporters. 
treatments. DRGs were randomly selected based on probability proportional to total expenditures from all payer sources in each DRG. To calculate these probabilities, the PPI analysts used the DRG frequency counts from the Hospital Cost and Utilization Project (HCUP), the average expenditure estimates from Medicare, and the DRG reimbursement rates published in the Federal Register. Due to the large number of DRGs, not all were used; 184 DRGs were chosen for the index based on revenue generation. DRGs were then randomly assigned to each hospital based on hospital characteristics provided in the sample frame.

In the cases where the hospital did not perform any services related to the assigned DRG, the field economist used a replacement DRG list to find a substitute DRG. The replacement DRG list was prepared specifically for each hospital and lists randomly selected alternative DRGs. The field economist started from the top of the list and worked down until a DRG was found that the hospital provided. In the case that a hospital provided the service, but refused to reprice the DRG, this was considered a refusal and no substitute was made for this DRG.

Once a DRG was assigned to a hospital, the price was obtained by the selection of a patient's bill, which serves as the measure of treatment and the basis for monthly repricing. A patient's bill lists the services provided during the entire length of stay and is conveniently presented in a standard format, uniform billing form UB-92 (formerly UB-82). This form is used by most hospitals and it lists a summary, usually by department, of the services provided. If physician fees and pharmacy charges are on the bill, they are included in the unit of measure. However, if these services are charged separately, then they belong to other SICs and are not part of the hospital unit of measure. Each hospital was asked to provide the last patient bill for each of the DRGs assigned to that hospital except in the case of the selection of a Medicare inpatient bill in SIC 8062. If a Medicare inpatient bill was selected for a SIC 8062 hospital, the hospital went to the next previous bill until a non-Medicare inpatient bill was selected for the assigned DRG.

Having selected a bill as the basis for price collection, the field economist next determined the expected reimbursement to the hospital. Because hospitals receive most payments for their services from third parties, they do not generally receive list prices as payments. Therefore, the price for hospital services is defined as the expected reimbursement from all payers for each patient bill. ${ }^{19}$ Five types of prices were encountered during data collection: list prices, list price less adjustments, case rate, per diem, and capitation.

19. In some cases, the hospital may receive payments for a bill from more than one payer. This would be the case in which the patient has a primary insurance carrier and a secondary carrier that covers items not paid by the primary. The price in this case would be the sum of all the individual payers' reimbursements. 
List prices were the net transaction price for hospital services for 45 percent of the initially collected data in 1992. This category includes those patients that pay the list price with or without any insurance compensation. ${ }^{20}$

Adjustments to list prices result from contract negotiations between hospitals and managed care organizations. Two common agreements for adjustments to list prices are discount from total charges and discount for prompt payment. Discounts from total charges typically range from 4 percent to 10 percent. The prompt payment discount is usually less and is given to insurance companies when payment is received within a specified time period, usually thirty days. Price movements for this price type can result from either changes in the line item price as documented on the patient bill or changes in the discount rates. Of the initially collected quotes in 1992, 19.4 percent were of this type.

Case rates are payments that are made for procedures (e.g., DRGs) or for illnesses remedied. This rate will normally cover all services required to treat the patient from admission to discharge. These rates are negotiated between the hospital and the payer on the premise that patients with similar diagnoses will receive similar services. Of the initially collected quotes, 20.7 percent were of this price type.

Some third-party payers prefer per diem rates. The per diem rate is the amount the hospital will be reimbursed per patient per day, regardless of the services provided by the hospital. This daily rate is multiplied by the length of the patient's stay to yield a total reimbursement. Under some contracts, the per diem rate is based on the type of room or bed patients occupy during their stay. The per diem rate is multiplied by the number of days at the hospital to obtain the price for the services. Of the initially collected quotes, 14.1 percent were of this price type.

Capitated reimbursement was the least common net transaction price encountered during the 1992 data collection. Capitation is a fixed, per capita amount paid to a hospital, regardless of the actual services provided or resources consumed by each patient. That is, the insurance company pays a hospital a fixed amount of money each month independent of whether policyholders enter it for treatment. This type of pricing shifts some of the risk from the insurance company to the hospital. Capitation accounted for 0.4 percent of the initially collected quotes. Capitation was deemed inconsistent with the index methodology for repricing because it is not a price per se-it is invariant to the service provided. Accordingly, these quotes were eventually removed from the sample.

20. Included in those without insurance coverage are patients who are ultimately designated as charity cases. This occurs because it is not known when a bill is generated whether a particular patient falls into such a category. The fact that a zero price is ultimately received does not create a problem qualitatively different from the general problem of having a difference between expected reimbursement and the amount the hospital actually receives. 
Hospitals also receive revenues for services other than medical treatments. Approximately 2.8 percent of total hospital revenue is derived from cafeterias, gift shops, and parking. To reflect these additional revenue sources, quotes were collected on parking, gift shop items, and cafeteria items. One hundred seven quotes ( 3.6 percent of the total) were assigned to collect data on these miscellaneous receipts.

The weights for the hospital price index are based on 1987 industry revenue data from Census of Service Industries undertaken by the Bureau of the Census. For SIC 8062, such revenue data were not available for the individual cells, the MDCs. PPI analysts therefore calculated these weights by summing the revenues of each DRG comprising a MDC. DRG revenue was computed by multiplying DRG frequencies from the 1986 Hospital Cost Utilization Project and the mean DRG payment from the Federal Register. The weight for miscellaneous receipts is a weighted average from actual collected data. The weights for SIC 8062 were updated in 1995 using the same methodology and the 1992 revenue data for the Census Bureau.

For SIC 8063, the weight is the total revenue for the industry as reported in the Census of Service Industries. The weight for each publication cell is the percentage of revenues it generates multiplied by the total revenues of the cell one level above it. For example, the weight for the publication cell, private hospitals, is the percent of revenues generated in private hospitals for non-Medicare patients times the total revenues for non-Medicare patients. The weight for miscellaneous receipts is a weighted average from actual collected data. The weights for SIC 8063 were updated in 1995 using the 1992 Census of Service Industries. The weights for SIC 8069 were calculated in a similar manner.

\subsubsection{Monthly Repricing of Output}

Each month the hospital contact (reporter) receives a repricing schedule based on the earlier selected patient bill. This bill includes the entire ICD9 and Current Procedural Terminology (CPT-4) sequence of treatments performed on the patient, the expected length of stay, the expected length of time spent in the operating room, and the nurse-to-patient ratio (according to hospital policy) in both the intensive care and general wards. Ideally, the reporter reviews this information when the repricing schedule is received and makes any appropriate changes. It is important to note that the BLS does not collect these characteristics every month; only changes in the levels first obtained are recorded. The reporter is not required to make any special calculations for repricing. ${ }^{21}$

Annually, the PPI industry analyst must calculate the Medicare Inpa-

21. Until January 1997 special repricing techniques were in place for many New York hospitals because they were paid at rates set by the state and these were changed only twice per year. 
tient Treatments Index component of the General Hospital Price Index. The Medicare index shows fiscal year (October to September) changes in DRG payments to hospitals by Medicare, keeping the sample of hospitals and DRGs that were selected in 1992 constant. The analyst computes the total Medicare reimbursement amount for the PPI sampled hospitals under the prospective payment system for all inpatient treatments performed, keeping the total (national) number of discharges constant.

\section{Substitutions, Changes in Quality, and New Services}

Occasionally, substitutions of new bills for the bills initially selected must be made. If possible, the hospital selects another bill within the same DRG. If that is not possible, another DRG within the same MDC is selected. On average, there are three to four substitutions per month in this industry.

Substitutions occur for a variety of reasons. One reason is that a hospital is no longer able to price a specific bill because the bill has been purged from the computer system. Another reason is that a new person has been assigned to fill out the schedule and cannot understand the origins of the information on the initial bill. A substitution will also be made if a hospital contact refuses to review the bill line by line in determining the new price. ${ }^{22}$

In rare cases, hospitals may make substitutions when they no longer have a contract with the selected insurance company/payer. Because a comparison between two different payers cannot be made, a link to show no change is performed. A link to show no change is a method of quality adjustment in which the new price is not compared to previous prices; a new base price is calculated so that future prices can be compared from this point forward.

Two sources of change in service quality are technical change, both product and process improvements, and oversight by government and insurers. An example of the former is arthroscopic techniques (microsurgery through small incisions in the body) which are steadily being introduced in place of the customary invasive surgery. The new techniques often result in less pain for the patient and less damage to body tissues, thereby reducing lengths of stay. An example of the latter is the recent attempt by many insurance companies to limit hospital stays for childbirth to twenty-four hours; this attempt ended when the government mandated forty-eight hours of coverage. In addition, there can be changes in the notion of the standard treatment. For example, as mentioned earlier, lithrotripsy can replace the surgical treatment of kidney stones and does not require a

22. When some bills were originally selected, they contained prices for many line items. Many reporters have the habit of only looking at the DRG group or the insurance company's name and estimating the price for the service by using the overall chargemaster list instead of looking at each line item. When the reporter refuses to review each line item, a simpler bill is substituted for the original. 
hospital admission. If the standard practice becomes lithrotripsy and the treatment being priced is the surgery, the price information received will not reflect current practice trends. All of these sources of change can detract from the usefulness of pricing a fixed basket of services whose quality is assumed to be constant over time. One of the ways that the PPI program generally tries to account for such changes in services is to resample an industry about every seven years.

Another approach is to identify indicators or characteristics of the service quality and adjust price changes for measured changes in quality. The determination of the relevant set of characteristics is a major concern of researchers; BLS is certainly not alone in trying to devise a method for quantifying the quality of hospital services. Many researchers have turned their attention to outcomes, specifically to mortality rates and to such measures as quality-adjusted life years. Regarding the potential use of mortality rates, Fixler and Jaditz (1997) showed that for a set of treatments where mortality is a likely outcome, the mortality rate provides an ambiguous signal of quality induced price change. As described above, the repricing form lists the following indicators of service quality: the expected length of stay, expected length of time in the operating room, and the nurse-to-patient ratio in both intensive care and general ward.

In the event of an identified change in quality, standard quality adjustment procedures of the PPI would be used. The following is an example of that procedure:

Suppose we have a hospital repricing a surgical treatment that originally was priced at $\$ 10,000$ and took 100 minutes in the operating room (at a cost of $\$ 50$ per minute). The procedure has been improved so that it only requires 90 minutes to complete the surgical treatment. The hospital reports that the price is still $\$ 10,000$. In this situation, the producer's costs decline by $\$ 500$ ( 10 minutes at $\$ 50$ per minute). Using the explicit quality adjustment formula, the industry analyst calculates the new base price for this procedure:

$$
\text { New Base Price }=\$ 10,000 \times \frac{\$ 10,000}{\$ 10,000-(-500)}=\$ 9,523.80 .
$$

Though the price remained the same, due to the quality change, there is really a 5 percent increase in the price:

$$
\text { Percent Change }=\frac{\$ 10,000-\$ 9.523 .80}{\$ 9,523.80} \times 100 \%=5 \% .
$$

Of course, the usefulness of the quality indicators on the PPI repricing form depends on the willingness of reporters to diligently review this information and update it as necessary. Even if the reporters were to update the indicators, the computation of a quality adjustment remains difficult. 
Generally, to calculate a quality adjustment, the reporter would have to provide information on what the price would have been without any of the service changes so that a dollar value of the change could be estimated. Unfortunately, reporters rarely have access to this type of information. In most cases, when referring to a single service, the reporter does not know the specifics of price determination.

It is not surprising, therefore, that to date quality adjustments have rarely been performed. Through 1995, there have been approximately fifty changes to the length of stay, and no reported changes in nurse-to-patient ratio or time spent in the operating room. The instances in which the PPI has been successful in computing a quality adjustment are in the cases where a service has been split into two services, or two services have been combined into one. In these cases, the industry analyst attempts to determine the price as if the coding had remained the same.

\subsubsection{Resampling and Future Plans}

A new sample of hospitals and hospital treatments will be selected and information from this sample is currently scheduled for publication in January 2001 . Research is currently underway to update the hospital pricing methodology to accommodate changes that have occurred in this industry since it was originally published in January 1993. One of these changes includes the addition of a methodology for pricing fairly new reimbursement methods used by both private insurers and public payers. Capitation is one such method that is an increasing share of payments from managed care organizations. ${ }^{23}$

Research into a new method of quality adjustment for hospital treatments has also begun. It is anticipated that some combination of frequency of treatment data from the MEDSTAT group, numerical values indicating health status (possibly using quality-adjusted life year data), along with accepted clinical treatment protocols for selected common ailments will be used to develop a quality adjustment model for this industry. This model will necessarily be limited to a few very common ailments where the industry has established treatment guidelines and frequency data for different treatment options are available.

A new publication structure is being developed for the new sample. Two new MDCs may be added to the publication structure: multiple significant trauma and human immunodeficiency virus infections. Inpatient and outpatient treatments will be combined into one cell. This merger potentially permits the capture of a price change that arises when there is a switch from inpatient care to outpatient care. Currently, in the event of such a

23. PPI is currently researching and testing a capitation methodology with physicians that might be implemented in the next hospital sample. Additionally in 2001, the MDC weights in 8062 will be constructed directly from MDC total charge data. 
switch, the link to show no change method is used and this precludes any cost savings from affecting the index.

As mentioned previously, the industry analyst currently calculates the Medicare portion of the index. In the next sample, the industry analyst will no longer perform this computation because the Medicare portion will be sampled and repriced in the same manner as the rest of the index.

\subsection{Physician Price Indexes}

\subsubsection{Industry Definition}

The Physicians Services Price Index was first published in 1994 with a base period of December 1993. The current index is based on research conducted in the early 1990s, and is soon to be resampled as described below.

The PPI industry definition is a combination of the SIC Manual definition for offices and clinics of doctors of medicine (SIC 8011) and the American Medical Association (AMA) specialty classification system. The SIC definition includes establishments of licensed practitioners having the degree of M. D. and engaged in the practice of general or specialized medicine and surgery, and the AMA system includes physicians who are organized to provide medical care, consultation, diagnosis, and/or treatment for patients. The AMA's specialty classification system includes general/family practice, internal medicine, general surgery and other surgical specialties, pediatrics, obstetrics/gynecology, radiology, psychiatry, anesthesiology, and other specialties. Only those establishments with physicians practicing medicine are included in this industry. Practicing physicians include all physicians who are actively providing medical services, those for whom the plurality of their revenue comes from patient care and not administration or research. With the implementation of NAICS, minor changes will occur to the physician industry definitions. Under NAICS, health maintenance organization (HMO) medical centers (NAICS 621491), offices of physicians, mental health specialists (NAICS 621112), and surgical and emergency centers (NAICS 621493) will no longer be grouped in the physician industry, but in their own respective industries.

Establishments in the industry are organized in a variety of ways. Included organizational forms are solo and two-physician practices, single specialty group practices/clinics, multispecialty group practices/clinics, general medical and primary care clinics, outpatient care facilities, ambulatory surgical centers, freestanding emergency medical centers, and urgent care centers. A solo practice is one physician working independently to administer medical care, consultation, diagnosis, and/or treatment to patients. Though the solo practitioner commonly works alone, a physician may work in an office with other physicians and still be considered in a solo practice as long as there is no sharing of patients. A two-physician 
practice involves two physicians sharing the practice and patient base. The physicians need not be involved in the same specialty, but typically they practice the same or related specialties. As defined by the AMA, a group practice is the provision of health care services by three or more physicians who are formally organized as a legal entity in which business and clinical facilities, records, and personnel are shared. Income from medical services provided by the group is treated as receipts of the group and distributed according to some prearranged plan.

\subsubsection{Sample Unit Information}

The sample frame used for SIC 8011 was drawn from the AMA's Physician's Masterfile and the Group Practice File. These files were chosen because they are more comprehensive; they include the number of physicians in the practice, which is a better proxy for practice revenue than is total employment, the usual PPI measure of size. The Masterfile includes one record for every practicing office-based physician in the United States, including those in a group practice. Each record indicates the primary employment of the physician (e.g., solo practice, two-physician practice, or group practice). This file also includes the current specialty of the physician. Because the Masterfile does not provide any composition of a group practice, the Group Practice file was used as a supplement to the Masterfile for group practices. A sample unit is defined as a physician practice, not the individual physician. Although it is possible for a physician to belong to more than one practice, a sample unit always represents only one practice. However, the sample unit may encompass more than one physical location. For example, the physician may have an office located next to a hospital, where the doctor renders inpatient care, and one located in a neighboring town to see patients.

The Masterfile was used to select the solo and two-physician offices; these two practice types were treated as being the same. Selecting these practices from the Masterfile was hindered by the fact that this file contained a record for all physicians, regardless of type of practice, and the fact that a physician in a group practice may also have a solo practice. To separate the group practice physicians from the solo/two-physician practices, PPI analysts removed all physicians from the file for whom a zero was recorded for the number of hours in solo practice.

The Masterfile was then stratified into ten specialty strata: the nine AMA specialty classes and a "no specialty" category. A total of 220 sample units was selected from the Masterfile. Because each record represented one physician, the sample units were selected with equal probability within a given stratum. Physicians were placed in each stratum based on their declared area of specialization. In this industry, primary specialization is determined by the number of hours spent in the field and not by percentage of total revenues generated.

The Group Practice File was used to select group practices. This file 
was stratified into twelve specialty strata: the nine AMA specialty categories, no primary specialty, multispecialty, and no specialty composition listed. A total of 180 sample units was selected from the Group Practice File. These sample units were drawn with probability proportional to the number of physicians in each group practice, within each explicit stratum. For records with the "number of physicians" field equal to zero or blank, a one was substituted to provide for a chance of selection.

The number of price quotes assigned to each practice was based on specialty and the number of physicians in the practice. Solo/two-physician practices and single specialty practices with three to six physicians were assigned four quotes each. Single specialty groups with seven to ten physicians and the specialties of radiology, psychiatry, and anesthesiology with seven or more physicians were assigned six quotes. Single group practices with more than ten physicians were assigned eight quotes. The exceptions to these quote allocations were group practices in internal medicine and surgery. For these specialties, groups with up to six physicians were assigned six quotes while groups with seven to ten physicians were assigned eight quotes. Ten quotes were assigned to the groups with more than ten physicians. For the multispecialty groups, six quotes were assigned to practices of six or fewer physicians, eight quotes were assigned for groups with seven to ten physicians, and ten quotes were assigned for groups with more than ten physicians. As of July 1997, there were approximately 761 quotes in the physician index.

The physician price index used 1987 industry revenue data from the Census of Service Industries to set the base period weights. Appendix table 6A.l presents the publication structure for the physician index. ${ }^{24}$ The four-digit cell weight was the total revenue as reported in the 1987 Census of Services Industries. To calculate the weights for the five-digit cells, the percent of revenue received from that payer type (Medicare or nonMedicare) was multiplied by the total revenues for primary services.

To calculate the weights for the six-digit cells, it was first necessary to determine the percentage of non-Medicare revenues in the cell. For each of the nine specialty categories, total revenues were calculated using average income (from AMA) multiplied by the number of physicians with that specialty who are in either a solo, two-physician, or single specialty group practice. The revenues for all specialty groups were summed together. This procedure was repeated with the number of physicians in a multispecialty group practice. The two revenue sums were then added together to calculate the percentage of revenue from solo and two-physician practices and single specialty group practices. This percentage was multiplied by the

24. Though the publication structure for physicians is based on practice specialty, it is not qualitatively different from the treatment-based structure in the hospital index because there is a correspondence between MDC and physician specialty. 
weight for non-Medicare treatments to arrive at the weight for solo and two-physician practices and single specialty group practices. The same procedure was used to calculate the weight for multispecialty groups.

The weights for the nine specialty seven-digit cells were calculated by taking the percentage of revenue generated by that specialty and multiplying it by the weight for solo and two-physician practices and single specialty practices. As with the hospital index, the 1992 industry revenue data from the Census of Services Industries were used to update the weights in 1995.

\subsubsection{Output and Price Determination}

BLS field economists visited the selected sample unit to determine the unique item that would be priced monthly. The item is selected according to a disaggregation process that depended on the practice characteristics and, at a minimum, the following variables were used: multiple-fee schedules, place of service of primary procedure, and type of payer. In a twophysician or group practice, the field economist was required to perform two disaggregations when the two physicians performed the same service but charged different rates. If a physician performed services at various locations and charged different rates, the field economist would be required to disaggregate between service locations. This circumstance may arise if the physician performed some procedures at his office and others at a clinic.

Accounting for payer type is important because physicians receive the majority of reimbursements for services from third-party payers, private and public, and because the type of payer affects the transaction price. The most common payer types include Medicare, Medicaid, private insurance (including managed health care), and out-of-pocket or self-pay.

In 1989, Medicare accounted for 23.4 percent of physician revenue. ${ }^{25} \mathrm{At}$ the same time, 44.1 percent of physicians were considered "participating" physicians; that is, they accepted Medicare and its fee assignment as payment in full. ${ }^{26}$ In 1996, Medicare accounted for 27.4 percent of physician revenue ${ }^{27} \mathrm{HCFA}$ directly reimburses participating physicians. Nonparticipating physicians can accept Medicare fee assignments but are reimbursed directly by the patient. As with the hospital price index, the prices for services covered by Medicare were computed by the Washington PPI office.

Medicaid is a program that is financed through a combination of state and federal funds and makes direct payments to enrolled physicians. Med-

25. 1989 data on payer type as percentage of physician revenues were obtained from the 1990 HCFA Symphony file which reports 1989 data.

26. In some cases, called outliers, Medicare acts as a fee-for-service insurance program reimbursing for costs. Such cases are truncated from the sample.

27. 1996 data on payer type as percentage of physician revenues were obtained from the American Medical Association Physician Market Place 1996. 
icaid programs and rates vary by state, but physicians must accept Medicaid reimbursement as payment in full. Unlike Medicare, there are no copayments or deductibles. In 1989, Medicaid accounted for 3.6 percent of physician revenue. By 1996, Medicaid accounted for 11.8 percent of physician revenue.

The reimbursements physicians receive from private health insurance depend on the type of insurance. HMOs, PPOs (preferred provider organizations), EPOs (exclusive provider organizations), and POS (point of service) providers usually provide reimbursement based on negotiated fee schedules. In most cases, these types of insurance require some copayment by the patient for services rendered. Another form of payment is provided by indemnity insurance, which is a fee-for-service type of reimbursement. Once the individual has covered the policy deductible, the private insurer will reimburse the doctor some percentage of the total billed amount and the patient is to cover the remaining portion of the bill. In 1989, private health insurance accounted for 47.6 percent of physician revenue. In 1996, private insurance had declined to 42.9 percent of physician revenue.

Out-of-pocket payments, or self-pay, accounted for 19 percent of total physician revenue in 1989. In 1996, out-of-pocket had decreased to 17.9 percent of physician revenue. In this situation, the patient is solely responsible for payment of the bill. ${ }^{28}$

The item selection process yielded a single patient bill, and a copy of it along with HCFA-1500 was requested from the reporter; these would be used for repricing. ${ }^{29} \mathrm{~A}$ limitation of using a single patient bill to price physician services is that it generally does not represent a full treatment. Consider a patient visit to a doctor for the treatment of a sinus infection. The physician may request the patient to return two weeks later for a follow-up visit. If the first visit was billed separately, the unique item (services) would only reflect the treatment received at that single visit. Billing for the complete treatment (all office visits, supplies, etc.) is referred to as "global billing." In the surgical and obstetrics/gynecology specialties, global billing is a common practice.

All selected items for repricing were coded into different product categories for this industry. The product codes are based on the specialties used to stratify the physicians previously. Each specialty represents a product

28. Copayments are part of an insurer's coverage; that is, they are captured as part of the price of the treatment to the insurer and not considered "out-of-pocket." From the PPI perspective there is no reason to decompose such payments into an insured and insurer component. The phrase "out-of-pocket" is reserved for the uninsured and so the revenue share provided by out-of-pocket patients refers only to those who do not have insurance.

29. The HCFA-1500 form is the required health insurance claim form for Medicare reimbursement for physicians and has been adopted as the standard health insurance claim form by many other payers. In those circumstances where the field economist could not transcribe all the information from the patient bill and HCFA-1500 or acquire a copy of the actual bill, the quote was to be coded as a "refusal." 
category. Each of these specialty categories also represented one of the publication goals for this index (see app. table 6A.1).

The transaction price for a physician service is defined as the expected reimbursement for one physician visit, except in the cases of global billing in which multiple visits are included. As in the case of hospitals, there can be a difference between the charge on the bill and the actual reimbursement. When a physician agrees to accept an insurer's negotiated fee as payment in full, then that is the net transaction price. Some physicians, however, will not enter into such agreements and will directly bill the patient the difference between the price charged for services rendered and the insurance coverage. This type of reimbursement practice is referred to as "balance billing." The net transaction price is then defined as the sum of the insurance payment and the patient payment. ${ }^{30}$

Managed care programs usually require that the patient make a copayment. Under most managed care agreements, the payer and physician negotiate a fee schedule as mentioned above. The net transaction price is the agreed-upon fee plus the patient copayment.

\subsubsection{Monthly Repricing of Output}

As part of the field economist's visit to the physician, a repricing plan is developed that enables the physician to price the identical service monthly. Each month, a repricing form is mailed to a physician practice. This schedule contains a shortened summary of the patient's actual bill that lists the diagnoses and procedures with the corresponding ICD-9 and CPT-4 codes, the medical services performed on the patient, and the supplies used. In addition, the schedule has a service identifier that indicates whether a hard copy of the bill is kept on hand in the office or is stored in a computer file. The reporter reviews this information and provides any changes. The reporter is not required to make any special calculations.

Annually, the industry analyst must calculate the Medicare portion of this index using data published by HCFA. This calculation shows the calendar year changes in physician payments by Medicare, keeping the services that were selected in 1992 constant.

\section{Substitutions and Changes in Quality}

Sometimes a substitution must be made for the item being repriced. Many of the reasons for substitutions are the same as those discussed under the hospital index. In addition to those reasons, substitutions have occurred in the physician index when the payer no longer reimburses for a specific ICD-9 or CPT-4. In this circumstance, a new ICD-9 or CPT-4

30. In some cases, a patient may have secondary insurance that may pay the copayment, the deductible, or the balance of the bill. In the example of the balance billing, the secondary insurance company would cover the share that the primary insurance company did not cover. 
that provides similar services and will be reimbursed by the payer is substituted. There have been a few instances when a physician has discontinued providing a specific service, in which case a comparably priced substitute is selected. On average, there are three to four substitutions per month in this industry.

As was described in the case of hospitals, physicians respond to changes in techniques, to the introduction of new goods and equipment, and to the demands by government and insurers to contain medical care delivery costs. In addition there are changes in physician skills and the efficacy of various treatments. Because such changes in quality are extremely difficult to measure and price, it is not readily possible to adjust the observed service price change for such changes in quality. ${ }^{31}$

As in the case of hospitals, quality adjustments are rarely performed in this industry. Again, the major problem in calculating the quality adjustment is the lack of appropriate information; for example, reporters do not generally know what the price of the service would be without the quality change. Consequently, when a change in quality is encountered, the link to show no change method is usually employed.

There are other problems encountered in repricing physician services. Many reporters have complained that their prices do not change often and therefore object to undertaking the work involved in supplying monthly price reports. Some have complained that even a quarterly report was too frequent. In some cases, the industry analyst has agreed to contact the reporter to get price updates rather than having the repricing forms sent directly to the reporter each month or quarter. In addition, there is the ever-present problem of ensuring that the reported price is a transaction price and not a list price.

As with the hospital index, erosion of the sample is occurring as the index ages. The main reason for the decline in quotes is due to reporters' requesting removal from participation because they are tired of completing the forms. The retirement of physicians is another reason for sample erosion.

\subsubsection{Resampling and Future Plans}

A new sample of physicians and physician treatments was drawn in 1999 and information from this sample was published with the indexes for Janu-

31. Unlike the case of hospitals, it was not possible to identify indicators of quality change to place on the repricing form. The potential impact of unmeasured quality change on observed price change might be somewhat lessened by the facts that (1) most changes in service quality manifest themselves in the form of changes in the CPT code, (2) new equipment may be too expensive for small practices to acquire, and (3) major changes in treatments arising from new or improved drugs take a long time to be approved and accepted. 
ary 2000 . In addition, a new capitation reimbursement methodology was implemented for the January 2000 physician index.

The January 2000 indexes also for the first time incorporated changes from the offices of osteopaths and ambulatory and surgical centers. Other changes in the indexes include the elimination of the distinction between Medicare and non-Medicare payers, the combination of the anesthesiology and radiology cells into an "other specialty" cell, and the introduction of a different method of computation for the Medicare portion of the index. With respect to the last, the industry analyst no longer calculates that portion of the index. Instead, the Medicare portion is sampled and repriced in the same manner as the rest of the index. One reason for this change is to allow the index to reflect the trend toward managed care in Medicare.

\subsection{Drug Price Indexes}

\subsubsection{Industry Definition}

The drug industry, SIC 283, consists of four components: medicinal chemicals and botanical products (SIC 2833), pharmaceutical preparations (SIC 2834), in vitro and in vivo diagnostic substances (SIC 2835), and biological products except diagnostic substances (SIC 2836). Generally, if a drug requires the approval of the Food and Drug Administration (FDA), it is placed in SIC 283. Other organic compounds are in SIC 2869; these substances do not require FDA approval. It should also be noted that pharmaceuticals manufactured in Puerto Rico, an important manufacturing center, are out of scope for the PPI. ${ }^{32}$

Under NAICS there will be some adjustment to the definition of the industry. SIC 2834 and part of 2835 will be combined into a NAICS category called diagnostic substances, except in vitro diagnostic. The remaining part of SIC 2835, in vitro diagnostic substances, makes up the entire NAICS category called in vitro diagnostic substance manufacturing. SIC 2834 is mapped into its own NAICS category.

32. In the case of drugs, like many other sophisticated products, the production process can spread across national boundaries. In the PPI, Puerto Rico is considered outside the United States, while for the official U.S. Import and Export Statistics and the Balance of Payments accounts, Puerto Rico is considered part of the United States. The BLS import price index for drugs, unfortunately, cannot be used to remedy this situation. First, both the import and export price indexes use the Balance of Payments definition of the United States and so there does not exist a direct measure of the importation of Puerto Rican goods into the United States. Indirect evidence, however, suggests that the volume of drug imports is relatively small, on the order of 8 percent of domestic drug production in 1996, though it appears that the number may be higher in 1997. Second, because the PPI drug index includes many more products than does the IPP import drug index, there is a small likelihood of matching products in the two indexes. 
For the entire three-digit category, the following represents the allocation of sales in the late 1980s: manufacturing 14.5 percent, wholesale 45.7 percent, service 17.1 percent, and all others 22.7 percent. However, within the four-digit categories there is considerable difference in the pattern of sales; SIC 2833 has a larger percentage of sales to manufacturing than does SIC 2834 or 2835 and these last two SICs have a large percentage of sales to wholesalers. A large percentage of sales in SIC 2836 is to services.

\subsubsection{Sample Unit, Output, and Price Determination}

The sample frame of manufacturers is selected from a list compiled from various industry lists, the Census of Manufacturers, and the unemployment insurance (UI) file. The sample sizes are for medicinal chemicals, 78 sample units; for in vitro and in vivo diagnostic substances, 69 units; for biological products, 54 units; and for pharmaceutical preparations, 270 units. All sample units are stratified by size, which is approximated by employment. Unit size in turn determines the number of price quotes to be collected from a unit, except in the case of pharmaceutical preparations.

For SIC 2833, 2835, 2836, and the nonprescription portion of SIC 2834, an establishment-based sample is selected by probability proportionate to employment. Products are selected from the selected establishments according to the disaggregation process in which the BLS field representative uses the sales share of products sold and a random number table to select a unique product to price. The current number of price quotes in each SIC is as follows: SIC 2833, 84 quotes; SIC 2835, 306 quotes; SIC 2836, 121 quotes; and the nonprescription portion of SIC 2834, 228 quotes. For all of these price quotes, the BLS field representative takes note of the product details, form, strength, and presentation along with transaction characteristics. These characteristics will form the basis for substitutions and quality changes.

For the prescription portion of the pharmaceutical preparations industry (SIC 2834), the number of price quotes was determined for each therapeutic class; the number of quotes was roughly based on the value of shipments for that class but was modified as needed to ensure a sufficient number of quotes to meet publication requirements. (Appendix table 6A.2 provides a list of the therapeutic class price indexes along with recent index levels.) The current number of quotes for this industry is 593 . Once the number of quotes was determined, a selection of drugs was made in each class according to probability proportional to prescription sales. All drugs in a class had a chance of selection. ${ }^{33}$ Next, the form and strength of the selected drugs were in turn selected on the basis of national sales data. ${ }^{34}$

33. Accordingly, a multiproduct manufacturer had a chance that every drug it made would be selected - - there was no limit imposed on the number of drugs selected from a manufacturer. 
These two samples were drawn in the Washington office. Having selected drug products and their form and strength, the drug products were combined by manufacturer into a sample unit for data collection. The number of products assigned to companies varied from one to about sixty. The presentation variables (unit of measure, type of sale, type of buyer, adjustments to price, etc.) were selected when the field representative visited the sample unit.

\section{Monthly Repricing of Output}

Every month, the PPI program sends to reporters (manufacturers) a pricing schedule, which contains the description of the product to be priced. As for all industries, the PPI seeks to collect transaction prices. One complication to obtaining transaction prices derives from the Medicaid rules about "best" price that require manufacturers to provide rebates to Medicaid. In 1991 these rebates amounted to $\$ 553$ million and in 1995 they amounted to $\$ 1,821$ million (PhRMA 1997). The tremendous growth in third-party payers has also raised other complications because of the different purchasing schemes of the various insurers.

The PPI repricing strategy is based on the assumption that the exact same product will be available every month. This assumption is often difficult to maintain because of the steady stream of new drugs and generics. A complete resampling of the pharmaceutical preparations SIC is scheduled to begin in 1999 and the in vitro and in vivo diagnostic substances SIC is currently being resampled. ${ }^{35}$

\subsubsection{New Drugs and Generics}

The pharmaceutical industry is one that is notably dynamically competitive. Firms engage heavily in research and development with the intention of introducing new products to increase profits. ${ }^{36}$ Because the patent protection for new drugs is finite, another dimension to the competitive nature of the industry is the introduction of generics. A common path for prices after the introduction of a generic is that the price of the pioneer goes up while the price of the generic falls over time ${ }^{37}$ These features create several difficulties for index number makers.

One issue in the handling of generics is the degree to which the generic is a substitute for the branded pioneer. Approval by FDA of a generic only

34. Tiwo national sales data sets were used: one with product information and one with form and strength information.

35. The resampling of the remaining component industries has not yet been scheduled.

36. R\&D expenditures by pharmaceutical companies increased by 11.5 percent over 1996 to reach a total of $\$ 18.9$ billion. Companies have more than doubled their $R \& D$ expenditures since 1990. More than 84 percent of pharmaceutical R\&D in the United States is geared toward new products. See PhRMA (1997).

37. See Berndt, Griliches and Rosett (1993). BLS researchers obtained similar findings; see Kelly (1997). 
requires bioequivalency to the pioneer. In the test for bioequivalency blood samples are collected from sixteen to twenty healthy patients (none with the condition to be treated) and a comparison is made between the levels of the generic and the pioneer drug found in the blood. Bioequivalency is declared if the generic has a +25 percent or -20 percent variation in bioavailability (the rate at which the drug is absorbed) when compared to the pioneer. If the generic also has the same ingredients so that it is pharmaceutically equivalent, then the generic is labeled therapeutically equivalent. Because the generic is not exactly identical to the branded pioneer, it is not a perfect substitute for it, as demonstrated by the coexistence in the market of the branded pioneer and the generic, at least for some duration. ${ }^{38}$

Until January 1996, the PPI program resampled the industry approximately every seven years and treated generics as separate new goods. ${ }^{39}$ However, this approach was criticized as being too slow in incorporating new goods, principally generics, and thereby caused the indexes to overstate price increases. ${ }^{40}$ The PPI method was also faulted for having including too many old drugs - newer drugs seem to have smaller price increases than older drugs. ${ }^{41}$

In January 1996 a supplemental sampling protocol was introduced to capture new products and it is to be applied annually. The supplemental sample is to be drawn from the FDA list of approved drugs since the time of the drawing of the last sample. The focus of the selection is on generics introduced because of patent loss and on new products. Once the drug products are selected the next step in the protocol is to determine their market share. In the case of generics, the percentage market share is applied to the dollar value weight of the pioneer to determine the dollar value weight for the generic. Also, the base price for the generic is set to the price of the pioneer at the time the generic is introduced into the index. Thus the PPI program effectively treats generics as being identical to the pioneer, which given the earlier discussion is arguable. The 1996 supplement contained all drugs approved between December 1992 and April 1995. In that supplement the market penetration of the generic was estimated, as explained in Kanoza (1996). In the January 1997 supplement market penetration was measured as the actual percent of dollar sales as reported to IMS, a private firm that collects information on pharmaceutical sales. The January 1998 supplement covered drugs approved in the twelve months between June 1996 and May 1997. IMS data were again

38. The introduction of a generic can, however, greatly affect the sales of the pioneer. In a study of fourteen new chemical entities, Grabowski and Vernon (1994) found that the average percentage decline in sales in the first four years following patent expiration were 30 percent, 21 percent, 12 percent, and 12 percent, respectively.

39. Samples were introduced in July 1981, January 1987, and January 1994.

40. See Berndt, Griliches, and Rosett (1993) and Griliches and Cockburn (1995).

41. This is not to suggest that generics and new drugs follow the same price trend after introduction. 
used to apportion the weight for generics having a branded predecessor in the index. The weight for new drugs was determined by value of shipment information collected from the manufacturer. ${ }^{42}$

It is important to note that the supplemental sampling focuses on specific drug products and not on therapeutic classes. The implication is that the addition of relatively more expensive drugs in a therapeutic class need not increase the measured movement of prices in that class. When the new drug is incorporated its price at the time becomes the base price and price movements are measured relative to that base. Thus only if the price change for the new drug was substantially greater than the other drugs in the class would the price of the therapeutic class increase. In short, it is the price change and not the price level that is the focus of attention.

\section{Quality Adjustment}

Accounting for the introduction of new drugs and generics is in a sense part of the issue concerning the measurement of changes in product quality. New drugs can be viewed as major changes in product quality while lesser changes in quality can include such features as changes in package size or dosage. ${ }^{43}$ In general PPI analysts look to changes in production costs as the measure quality change. As described below, such a procedure is of limited usefulness in this industry and, correspondingly, quality adjustments are rare in this industry.

In many cases, certainly for new active ingredients, the major contributor to cost is not production cost but rather the underlying research and development (R\&D) cost. Grabowski and Vernon (1994) show, however, that it is difficult to amortize R\&D costs and to compute the cost of developing a new drug. ${ }^{44}$ Accordingly, substantive changes in products, such as the inclusion of new active ingredients, are usually treated as new products. This is consistent with the fact that when drugs contain new active ingredients they are given a new National Drug Code (NDC) designation. As described above, the PPI program captures the introduction of these new products through its supplemental sampling procedure.

In the case of changes in presentation, inactive ingredients, or other such lesser changes in quality, the attendant changes in production cost are used when available. If they are unavailable, then other methods of quality adjustment are used, such as the overlap method or link to show no change. ${ }^{45}$

42. See Kelly (1997) for more discussion of the current supplemental sampling procedure.

43. Product line extensions are also common. Yet in such an event it is assumed that the original product is still available, in which case the price of the original product would be collected.

44. In addition, there are also the costs, in both time and money, associated with the clinical trials necessary for FDA approval. The current estimate of the average length of time required to develop a new drug is about fifteen years. See PhRMA (1997), chap. 2.

45. In the overlap method the new product's base price is computed as the base price of the old product multiplied by (new product price in $t-1$ old product price in $t-1$ ). Note that both the prices of the new product and old product have to be available in $t-1$ for the 
As mentioned at the outset the case of pharmaceutical products is somewhat different from the other health care indexes because they are manufactured and thereby avoid some of the measurement problems associated with services. In short, the focus is on the physical product and not on a treatment for a condition or illness. If the focus were to shift to treatments then one would also have to overcome the hurdle of the boundaries imposed by the SIC system now and NAICS in the near future. For example, there is no mechanism for incorporating changes in physician services that derive from changes in pharmaceutical products. Part of the problem is that the treatments associated with the sampled drugs may not correspond to the treatments in the sampled physician services. How to account for the interaction among different industries of changes in quality is an important issue because it bears on the measurement of treatment quality, an issue that is addressed by other papers in this volume.

\subsection{Medical Laboratories}

\subsubsection{Industry Definition}

PPI began the development of the medical lab index in the early 1990 s and first published the index in July 1994 with a base period of June 1994. The 1987 Standard Industrial Classification Manual defines medical laboratories (SIC 8071) as establishments primarily engaged in providing professional analytic or diagnostic services to the medical profession or to the patient on prescription of a physician. For inclusion in this industry, BLS requires the laboratory to receive a plurality of its revenue from laboratory testing and the laboratory must be financially and operationally separate from the hospital or physician practice, with its own employment and recordkeeping. The revenue earned by laboratory testing in a physician practice is assigned to SIC 8071 only if testing is performed for patients from other practices.

Under NAICS there will be some adjustment to the definition of the industry. SIC 8071 medical laboratories will be split into two separate categories. Diagnostic imaging centers will form its own NAICS category called diagnostic imaging centers (NAICS 62151). Medical laboratories except diagnostic imaging centers will form the NAICS category called medical laboratories (NAICS 621511). In 1989, the Service Annual Survey estimated that SIC 8071 receipts were $\$ 8,396$ million or 2.1 percent of the estimated $\$ 403,009$ million in receipts for health services. They have remained approximately at that level.

overlap method to be used. If the price of the new product in $t-1$ is unavailable then the link to show no change method is used; the ratio of prices becomes (new product price in $t /$ old product price in $t-1$ ). 


\subsubsection{Sample Unit, Output, and Price Determination}

The sample of medical labs was selected from the UI file. The frame was stratified into radiology labs and all other labs. Twenty-seven sample units were allocated to the radiology stratum and ninety-three units to all other stratum. Four to six quotes were allocated to each sample unit except for certainty units, which were allocated eight quotes. A certainty unit is a firm that was automatically included in the sample due to its level of employment. The major tests included in the index are automated, multichannel, urinalysis, chemistry, toxicology, therapeutic drug monitoring, hematology, immunology, microbiology, pathology, profiles and panels, and $\mathrm{x}$-ray.

For all price quotes at the time of initiation (1992), the field economist recorded the test name, code, payer type, and any discounts. When panel tests were selected as the service for pricing, it was imperative that the field economist record all the tests included in the panel. This information would form the basis for substitutions and quality changes.

In this industry the two major price-determining factors are the services provided and the payer type. Services of medical laboratories are coded by CPT- 4 code, which represent a wide range of laboratory and pathological services. Each CPT-4 code has a corresponding reimbursement rate. Types of payers include wholesale payers (physicians and hospitals) and retail payers (insurance companies, Medicare, Medicaid, and patients). Wholesale payers tend to receive discounts from the labs in exchange for the large volume of services that could potentially be referred. In many cases, wholesale payers receive one bill a month for all lab work. Retail payers, on the other hand, usually pay higher prices for the same tests and are billed for each visit separately.

\subsubsection{Substitution and Changes in Quality}

In this industry there are two main reasons for substitution: The lab no longer provides a specific service or the lab's contract with a payer no longer exists. In both of these cases, new tests are substituted, and ideally the new tests belong to the same major service type as the original tests. A link to show no change is performed when making these substitutions. The few quality adjustments performed were to account for changes in the tests that comprise a panel or profile of tests. Due to the increase of managed care and the desire to reduce costs, occasionally a test will be removed from a profile or panel. In these rare cases, an explicit quality adjustment is calculated; in other words, the price is adjusted to reflect the removal of one or more of the tests from the profile or panel.

Erosion of the sample has occurred. Many of the establishments sampled have merged with others in the sample and the resulting consolidation accounts for a large percentage of the decrease in the sample size. 
Additionally, as in the other health industries, reporters have tired of completing the forms; in this industry prices are relatively stable and so reporters view monthly repricing forms as unnecessary. As a result of the high level of sample erosion, PPI accelerated the collection of a new sample for this industry and published an index based on a new sample in January 1999.

\subsection{Nursing Homes}

\subsubsection{Industry Definition}

PPI began publication of the Nursing Home Index in January 1995 with a base period of December 1994. The development effort on this index began in the late 1980s and at that time nursing homes were classified either as skilled nursing facilities or as intermediate care facilities. On 1 October 1990, the regulatory distinctions between these two categories were eliminated. Responding to this change, BLS formed a new SIC, SIC 8053, entitled skilled and intermediate care facilities. This SIC is a combination of SIC 8051, skilled nursing care facilities, and SIC 8052, intermediate care facilities. For this SIC, nursing homes are defined as establishments primarily engaged in providing inpatient nursing and rehabilitative services to residents. The staff must include a licensed nurse on duty for eight consecutive hours per day, seven days per week. Facilities included in this industry are skilled nursing facilities, intermediate care facilities, convalescent homes with continuous nursing care, extended care facilities, and mental retardation hospitals not funded solely by state or federal money.

With the implementation of NAICS minor changes will occur in the nursing home industry definitions. NAICS 62311 will include skilled nursing care facilities except continuing care retirement communities, intermediate care facilities except mental retardation facilities and continuing care retirement communities, and other nursing and personal care facilities formerly included in SIC 8059.

\subsubsection{Sample Unit Information}

The UI file was used as the sample frame for nursing homes. The UI file was stratified by the former SIC codes 8051 , skilled nursing facilities, and 8052, intermediate care facilities. As with the hospital sample, those facilities that are operated and funded solely by state or federal governments were truncated. One hundred twenty sample units were selected from former SIC 8051 and thirty sample units were selected from former SIC 8052. Four to six quotes were assigned to each sample unit based on the sample unit's employment size. 


\subsubsection{Output and Price Determination}

Once the sample units were selected, the field economists conducted interviews with the staff at these units. The first step of selecting pricing items (disaggregation) was to choose between primary and miscellaneous services. For this industry, miscellaneous services include all pharmacy activity and any services or items provided by the establishment to nonresidents, where nonresidents include patients' guests and adult daycare or nightcare patients. Next, the field economist disaggregated by payer type. If the payer type selected was either out-of-pocket, Medicaid, or private insurance, further disaggregation by level of care (i.e., moderate supervision, intermediate care, or skilled care) was conducted. If Medicare was the selected payer, then the level of care selected had to be skilled care. Once the disaggregation process was completed, the latest bill that matched the results of the disaggregation process was selected. The bill selected could be for an entire stay or an interim bill, whichever was the shorter period. The services provided on this bill became the unique item for repricing.

In this industry, the standard price is expressed as a per diem rate. However, the services included in the per diem rate vary by facility. In many cases, an individual bill will include the per diem rate plus line items for additional services provided to the patient. As with hospitals and physicians, the definition of price is the expected reimbursement for a patient's bill, whether it is for the entire stay or an interim period.

As with the other health care services, the type of payer (Medicaid, Medicare, private insurance, and individual) affects nursing home prices. The case of Medicaid is straightforward because the reimbursement to the nursing home is set, though the level of reimbursement varies across states as each state may use its own payment methodology to determine reimbursements. Medicare also sets the reimbursement level. These reimbursements vary by geographic region. Medicare nursing home benefits, which fall under Medicare Part A, cover short-term coverage of certain skilled services required by patients recovering from a recent acute illness rather than long-term or custodial care.

In addition to these government sources of payment, there is also the relatively recent growth in private insurers offering long-term care insurance. These policies typically pay charges up to some limit, after which the patient assumes responsibility. The final major payer type is the individual who must pay the full per diem rate plus any additional charges out of pocket. For those who must remain in a nursing home for a long period, assets are usually depleted quickly and then they become eligible for Medicaid. 


\subsubsection{Substitutions and Changes in Quality}

Substitutions are rare in this industry. When they have been performed, it was the result of the nursing home no longer having a contract with an insurance company. As with the other health services, a new patient bill is selected and a link to show no change is performed.

Quality adjustments are also rare for this industry. In principle, a quality adjustment would be made if there were an explicit change in the service bundle, such as the deletion or addition of a type of service. Usually, in such instances, the analyst performs a link to show no change because it is difficult to measure the associated change in cost. A quality adjustment would also be performed when the health status of patients change, even if there are no attending changes in the types of services included. The reason is that deterioration in a patient's health status, the usual occurrence, translates into a higher per diem rate. Medicare and Medicaid determine their per diem reimbursement rates based on the total cost reported by the facility, and so reimbursement rates would go up with a decrease in patient health because patients would require more of the services previously supplied. Thus it would be incorrect to record the increase in the per diem rate as a pure price change. Accordingly, when the health status of patients changes, the analyst performs the link to show no change adjustment procedure on the reported price.

\subsection{Other Related Indexes}

\subsubsection{Home Health Care}

The PPI program began publication of a home health care index in January 1997. In the SIC system home health care establishments are defined as those primarily engaged in providing skilled nursing or medical care in the home, under the supervision of a physician. Home health care services tend to be offered by home health care agencies. Agencies typically employ three or more staff members, offer at least two services and provide services in the patient's home.

The primary services associated with home health care usually fall into six categories as defined by Medicare: skilled nursing, physical therapy, occupational therapy, speech pathology, medical social service, and home health aide services. Accordingly, the unit of output for this index was set as the services provided during one visit, conditioned on the level of the provider (i.e., skilled nurse; RN; LPN; physical, occupational, or speech therapists; etc.), and the price was set as the per visit cost. Because services are priced on a per visit basis, the PPI approach captures all services performed within a visit as long as the services are included in the per visit cost. 
For this industry, the two major price-determining characteristics are the type of payer and type of provider. Type of payer (Medicare, Medicaid, private insurance companies, HMOs, and self-paying patients) is the most important characteristic for price determination. As such, the index publication structure is based on payer type (Medicare and non-Medicare) and provider type (see app. table 6A.1). Because the home health care index is relatively new, there have been no issues relating to substitution of services or quality adjustment. One reason for the lack of substitution is that most are reporting expected reimbursements based on the provider type.

Minor erosion of the sample is occurring. The sample unit allocation was 225 establishments. In the past year, approximately 6 establishments have been deleted. Most requested removal because they were tired of completing forms given that prices rarely change.

\subsubsection{Health Insurance}

Research is currently being conducted on the development of a price index for the health insurance industry. Under the SIC classification, two industries, accident and health insurance (SIC 6321) and hospital and medical service plans (SIC 6324) provide what is generally called health insurance. These industries are contained in the insurance carriers group of the SIC system. The SIC Manual defines establishments providing accident and health insurance as those establishments which provide health insurance protection for disability income losses and medical expense coverage on an indemnity basis. The hospital and medical service plan industry is defined as those establishments primarily engaged in providing hospital, medical, and other health services to subscribers or members in accordance with prearranged agreements or service plans. With the implementation of NAICS, these two industries will be combined into the same industry classification code, NAICS 524114. The expected publication date has yet to be determined.

\subsection{Summary}

In this paper we have provided a relatively thorough description of the Producer Price Indexes for the main industries comprising the health care sector of the economy. Because the focus is on industry output prices, consumer or patient welfare is not a component of the underlying conceptual framework. The discussion of each index included a description of sampling issues, the determination of price and output, monthly repricing, adjustments for changes in quality, and new goods.

In the health care area there are clearly many difficult measurement issues that index number makers must address. The consequent "practical cuts" are almost by definition inferior to the procedures that the PPI program would ideally like to employ. By identifying these issues we hope that 
we will not only provide users a better understanding of the indexes but also stimulate research on how the indexes might be improved.

Nevertheless, the PPI indexes provide valuable information by enabling medical service expenditure movements to be decomposed into price and output movements. More specifically, the Bureau of Economic Analysis (Department of Commerce) uses the individual PPI health care indexes and the aggregate health services index (for those services classified in health services [SIC 80]-published since 1995) as a deflator in various components of the National Income and Product Accounts. Because the SIC system is the basis for the PPI indexes they are applicable to the medical services included in the National Health Accounts (NHA)-these accounts include medical services provided by establishments that fall into SIC 80 or are provided by government operations that mimic that classification. The NHA, like the PPI, tend to collect reimbursement amounts for services provided (not list prices) and include nonpatient revenues such as gift shops and parking. Thus the PPI is essential to the determination of real output of medical providers in the various SICs, and for the output measures in the NHA. By implication, the indexes are important to the construction of productivity measures for the health care sector. Finally, these health care price indexes are also used as measures of inflation. These indexes are used to escalate wage contracts as well as contracts for services, such as those between firms and health care providers. 


\section{Appendix}

Table 6A.1

Publication Structure for Health Services Producer Price Indexes

\begin{tabular}{|c|c|c|c|c|c|}
\hline \multirow[b]{2}{*}{ Industry and Product } & \multirow{2}{*}{$\begin{array}{l}\text { Industry } \\
\text { Code }\end{array}$} & \multirow{2}{*}{$\begin{array}{l}\text { Product } \\
\text { Code }\end{array}$} & \multirow{2}{*}{$\begin{array}{l}\text { Index, } \\
\text { July } 1998\end{array}$} & \multicolumn{2}{|c|}{$\begin{array}{c}\text { Percent Change to July } 1998 \\
\text { from }\end{array}$} \\
\hline & & & & July 1997 & June 1998 \\
\hline Health services & 80 & & 107.6 & 1.3 & 0.1 \\
\hline Offices and clinics of doctors of medicine & 8011 & & 111.1 & 1.6 & -0.2 \\
\hline Primary services & & 8011-P & 111.1 & 1.6 & -0.2 \\
\hline Medicare treatments & & $8011-1$ & & & \\
\hline Medicare treatments & & $8011-101$ & 110.5 & 4.4 & 0 \\
\hline Non-Medicare treatments & & $8011-3$ & 111.1 & 1.0 & -0.2 \\
\hline \multicolumn{6}{|c|}{ One- and two-physician practices and single } \\
\hline specialty group practices & & $8011-31$ & 110.6 & 0.6 & -0.2 \\
\hline General/family practice & & $8011-311$ & 115.0 & 3.1 & -0.1 \\
\hline Internal medicine & & $8011-312$ & 111.7 & 0.4 & 0 \\
\hline \multicolumn{6}{|l|}{ General surgery and other surgical } \\
\hline specialties & & $8011-313$ & 105.2 & -0.7 & 0 \\
\hline Pediatrics & & $8011-314$ & 124.8 & 1.8 & 0 \\
\hline Obstetrics/gynecology & & $8011-315$ & & & \\
\hline Radiology & & $8011-316$ & 98.2 & 0 & 0 \\
\hline Psychiatry & & $8011-317$ & 106.8 & 0 & 0 \\
\hline Other specialty & & $8011-319$ & 108.0 & -2.1 & -1.9 \\
\hline Multispecialty group practices & & $8011-33$ & & & \\
\hline Multispecialty group practices & & $8011-331$ & 113.2 & 2.4 & -0.1 \\
\hline
\end{tabular}

(continued) 


\begin{tabular}{|c|c|c|c|c|c|}
\hline \multirow[b]{2}{*}{ Industry and Product } & \multirow{2}{*}{$\begin{array}{l}\text { Industry } \\
\text { Code }\end{array}$} & \multirow{2}{*}{$\begin{array}{l}\text { Product } \\
\text { Code }\end{array}$} & \multirow{2}{*}{$\begin{array}{l}\text { Index, } \\
\text { July } 1998\end{array}$} & \multicolumn{2}{|c|}{$\begin{array}{l}\text { Percent Change to July } 1998 \\
\text { from }\end{array}$} \\
\hline & & & & July 1997 & June 1998 \\
\hline Skilled and intermediate care facilities & 8053 & & 118.9 & 3.1 & 0.3 \\
\hline Primary services & & 8053-P & 119.2 & 3.2 & 0.3 \\
\hline Public payers & & $8053-1$ & & & \\
\hline Public payers & & $8053-101$ & 119.4 & 2.8 & 0.4 \\
\hline Private payers & & 8053-3 & & & \\
\hline Private payers & & 8053-301 & 119.0 & 3.7 & 0 \\
\hline Other receipts & & 8053-SM & 108.6 & 1.5 & 0 \\
\hline Hospitals & 806 & & 114.4 & 0.8 & 0.2 \\
\hline General medical and surgical hospitals & 8062 & & 114.5 & 0.6 & 0.1 \\
\hline Primary services & & 8062-P & 114.7 & 0.6 & 0.2 \\
\hline Inpatient treatments & & $8062-1$ & 113.5 & 0.3 & 0.1 \\
\hline Medicare patients & & $8062-131$ & 108.0 & -1.0 & 0 \\
\hline All medical diagnosis related groups & & $8062-13101$ & 107.0 & -1.4 & 0 \\
\hline All surgical diagnosis related groups & & $8062-13103$ & 109.1 & -0.6 & 0 \\
\hline Medicaid patients & & $8062-151$ & 109.8 & -1.2 & -1.2 \\
\hline All other patients & & $8062-171$ & 117.8 & 1.4 & 0.5 \\
\hline \multicolumn{6}{|l|}{ Diseases and disorders of the nervous } \\
\hline system & & $8062-17101$ & 108.5 & 0.2 & 0 \\
\hline Diseases and disorders of the eye & & $8062-17102$ & 112.0 & 2.2 & 0 \\
\hline $\begin{array}{l}\text { Diseases and disorders of the ear, nose, } \\
\text { mouth, and throat }\end{array}$ & & $8062-17103$ & 116.0 & 1.0 & 0.4 \\
\hline Diseases and disorders of the respiratory & & & & & \\
\hline system & & $8062-17104$ & 120.3 & 1.0 & 0.4 \\
\hline $\begin{array}{l}\text { Diseases and disorders of the circulatory } \\
\text { system }\end{array}$ & & $8062-17105$ & 118.9 & -0.3 & 0.1 \\
\hline
\end{tabular}


Diseases and disorders of the digestive system

Diseases and disorders of the hepatobiliary system and pancreas

Diseases and disorders of the

musculoskeletal system and connective

tissue

$8062-17108$

8062-17109

116.1

2.0

2.0

subcutaneous tissue, and breast

Endocrine, nutritional, and metabolic diseases and disorders

$8062-17111$

115.5

$8062-17112$

124.7

urinary tract

Diseases and disorders of the male reproductive system

$8062-17113$

121.3 reproductive system

Pregnancy, childbirth, and puerperium

$8062-17114$

$8062-17115$

118.2

Newborns and other neonates with

conditions originating in the perinatal

period

8062-17116

119.5

blood forming organs and immunological disorders

$8062-17117$

134.6

4.2

Myeloproliferative diseases and disorders,

and poorly differentiated neoplasms

$8062-17118$

119.4

3.4

Infectious and parasitic diseases (systemic

$8062-17119$

Mental disorders and diseases

$8062-17121$

111.1

Alcohol/drug use and alcohol/drug induced

organic mental disorders

$8062-17122$

116.3

0

4.3

123.4

4.0

0.8 


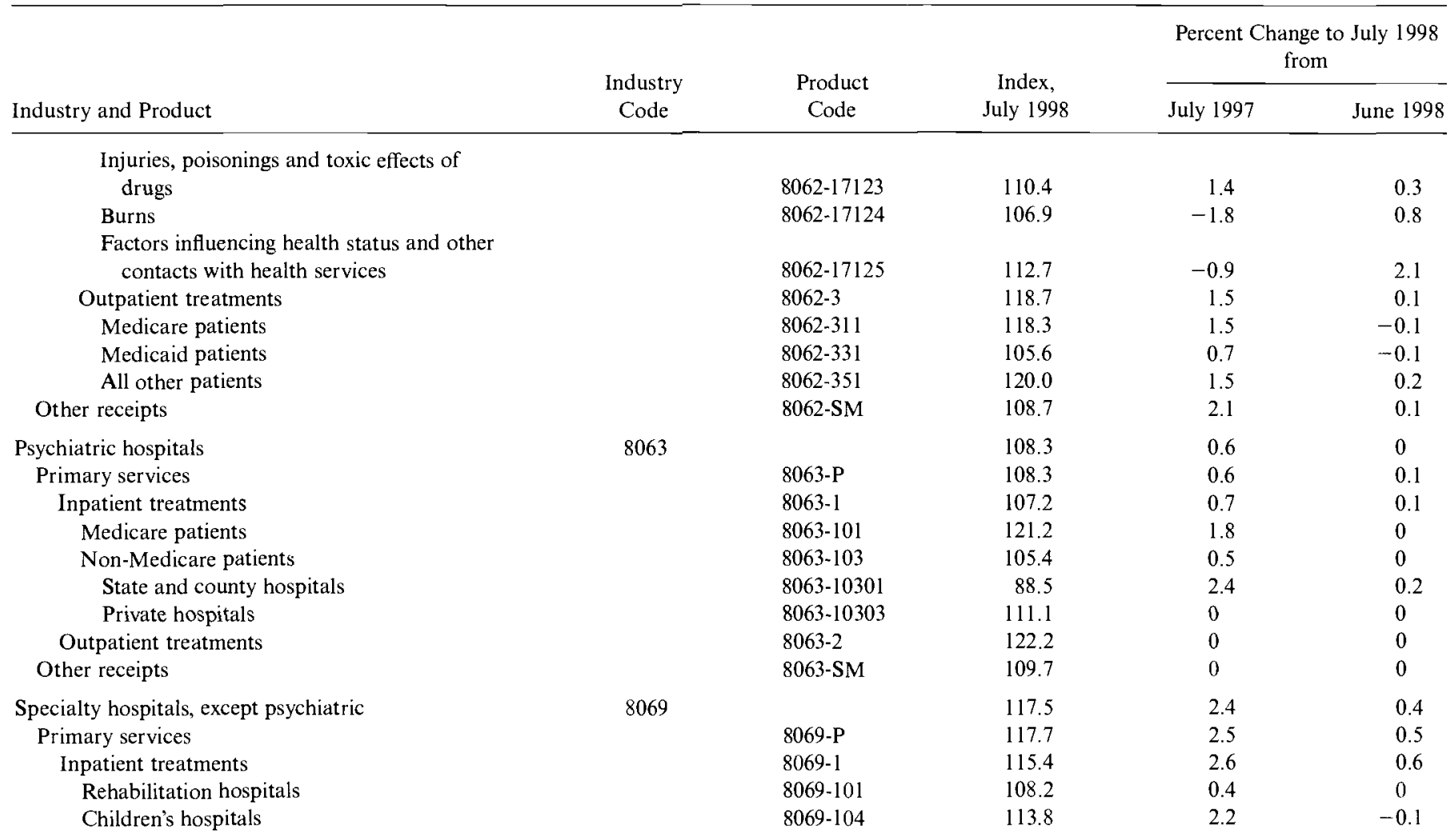


Alcoholism and other chemical dependency hospitals

Other specialty hospitals, except psychiatric Outpatient treatments

Other receipts

Medical laboratories

Primary services

Pathology and laboratory

Urinalysis

Chemistry, toxicology, and therapeutic drug monitoring

Hematology

Pathology

Profiles and panels

Radiological tests

Home health care services

Primary services

Medicare payers

Skilled nurse

Home health aide

Other provider

Non-Medicare payers

Skilled nurse

Home health aide

Other provider

\begin{tabular}{rlrrr} 
& $8069-107$ & 121.9 & 0.1 & 0 \\
& $8069-108$ & 121.1 & 4.9 & 1.9 \\
$80671-3$ & 125.8 & 2.0 & 0 \\
& $8069-\mathrm{SM}$ & 111.2 & 3.0 & 0 \\
& & 106.4 & 0.2 & -0.1 \\
& $8071-\mathrm{P}$ & 106.7 & 0.1 & -0.2 \\
$8071-1$ & 106.7 & 0.2 & -0.1 \\
$8071-102$ & 127.8 & 0.3 & 0 \\
& & & -0.4 \\
& $8071-103$ & 97.3 & 0.1 & -0.2 \\
$8071-104$ & 127.8 & 0.7 & 0.1 \\
$8071-107$ & 103.6 & -1.1 & 0 \\
$8071-108$ & 103.3 & 0.5 & 0.1 \\
$8071-3$ & 102.2 & -2.0 & -0.1 \\
& & 106.0 & 2.1 & -0.2 \\
& $8082-\mathrm{P}$ & 102.9 & 1.9 & -0.5 \\
& $8082-1$ & 103.2 & 1.2 & -0.5 \\
$8082-101$ & 104.8 & 1.9 & -0.4 \\
$8082-102$ & 101.5 & 0.4 & -0.4 \\
& $8082-103$ & 101.7 & 0.6 & 0.1 \\
$8082-2$ & 102.8 & 2.4 & 0.1 \\
$8082-201$ & 102.7 & 2.4 & 0.4 \\
$8082-202$ & 104.7 & 3.7 & -0.7 \\
$8082-203$ & 99.3 & -0.5 & 0.1 \\
\hline $8082-S M$ & 163.9 & 4.5 & \\
\hline
\end{tabular}

Source: U.S. Department of Labor, Bureau of Labor Statistics, PPI detailed report for July 1998.

Note: The publication structure shown was the one in place at the time of the conference. As described in the text, some changes were made in January 2000. 


\begin{tabular}{|c|c|c|c|c|c|}
\hline \multirow[b]{2}{*}{ Industry and Product } & \multirow{2}{*}{$\begin{array}{l}\text { Industry } \\
\text { Code }\end{array}$} & \multirow{2}{*}{$\begin{array}{l}\text { Product } \\
\text { Code }\end{array}$} & \multirow{2}{*}{$\begin{array}{l}\text { Index, } \\
\text { July } 1998\end{array}$} & \multicolumn{2}{|c|}{$\begin{array}{c}\text { Percent Change to July } 1998 \\
\text { from }\end{array}$} \\
\hline & & & & July 1997 & June 1998 \\
\hline Drugs & 283 & & 207.3 & 12.3 & 1.3 \\
\hline \multicolumn{6}{|l|}{ Medicinal chemicals and botanical products (in } \\
\hline Primary products & & 2833-P & 134.0 & 1.4 & 0 \\
\hline Synthetic organic medicinal chemicals & & $2833-1$ & 133.6 & 1.4 & 0 \\
\hline Central stimulants and depressants & & $2833-131$ & 71.8 & 8.5 & 0 \\
\hline \multicolumn{6}{|l|}{ All other synthetic organic medicinal } \\
\hline chemicals & & $2833-1861$ & 110.3 & 0.8 & 0 \\
\hline Other medicinals and botanicals & & $2833-3$ & 131.8 & 1.4 & 0 \\
\hline All other organic medicinals & & $2833-398$ & 133.6 & 2.1 & 0 \\
\hline Secondary products and miscellaneous receipts & & 2833-SM & & & \\
\hline Secondary products & & 2833-S & 146.8 & 4.3 & 0 \\
\hline Other secondary products & & 2833-SSS & 134.1 & 0.8 & 0 \\
\hline Pharmaceutical preparations & 2834 & & 298.2 & 15.2 & 1.6 \\
\hline Primary products & & 2834-P & 321.5 & 17.5 & 1.4 \\
\hline Pharmaceutical preparations, prescription & & $2834-1$ & 377.9 & 22.5 & 1.8 \\
\hline Analgesics & & 2834-102 & 451.7 & 9.2 & 4.4 \\
\hline Narcotic analgesics & & $2834-1021$ & 423.2 & 13.2 & 5.5 \\
\hline Nonnarcotic analgesics & & $2834-1022$ & 448.9 & 6.7 & 3.7 \\
\hline Synthetic, including acetaminophen and & & & & & \\
\hline antimigraine & & $2834-10221$ & 421.7 & 6.3 & 3.7 \\
\hline Antiarthritics & & $2834-105$ & 191.5 & -1.2 & -2.6 \\
\hline Anticoagulants & & $2834-106$ & 161.8 & 17.3 & 3.7 \\
\hline Anticonvulsants & & $2834-107$ & 256.0 & -33.5 & 9.6 \\
\hline
\end{tabular}


Systemic antihistamines

2834-109

2834-111

2834-1111

2834-11111

Broad and medium spectrum antibiotics

Cephalosporins

Broad spectrum penicillins

Other broad and medium spectrum antibiotics

Systemic penicillins

Antispasmodic/antisecretory

Bronchial therapy

Cancer therapy products

Cardiovascular therapy

Antihypertensive drugs

\section{Vasodilators}

Other cardiovasculars

CNS stimulants/antiobesity preparations

Cough and cold preparations

Oral cold preparations

Other cough and cold preparations

Dermatological preparations

Acne preparations

Fungicides

Topical anti-infectives

Other dermatological preparations

Diabetes therapy

Diuretics

Hormones

Hospital solutions

Muscle relaxants

Nutrients and supplements

Ophthalmic and otic preparations
2834-11112

2834-11119

2834-11129

2834-116

2834-118

2834-119

2834-121

2834-12119

2834-12129

2834-12191

2834-123

2834-125

2834-12511

2834-12519

2834-126

2834-12611

2834-12619

2834-12631

2834-12691

2834-127

2834-128

2834-135

2834-136

2834-139

2834-141

2834-142
481.3

241.5

213.5

289.7

103.3

221.0

388.6

510.0

548.9

358.5

371.2

316.8

349.4

777.5

476.7

264.5

399.0

107.8

505.1

262.3

352.7

261.8

84.5

311.3

376.5

384.5
0

$-0.1$

0

$-0.1$

0.2

6.3

$-0.1$

0.7

0.2

0.1

2.4

2.1

1.3

2.8

0

1.2

3.8

0.5 (continued) 


\begin{tabular}{|c|c|c|c|c|c|}
\hline \multirow[b]{2}{*}{ Industry and Product } & \multirow{2}{*}{$\begin{array}{l}\text { Industry } \\
\text { Code }\end{array}$} & \multirow{2}{*}{$\begin{array}{l}\text { Product } \\
\text { Code }\end{array}$} & \multirow{2}{*}{$\begin{array}{l}\text { Index, } \\
\text { July } 1998\end{array}$} & \multicolumn{2}{|c|}{$\begin{array}{l}\text { Percent Change to July } 1998 \\
\text { from }\end{array}$} \\
\hline & & & & July 1997 & June 1998 \\
\hline Psychotherapeutics & & $2834-144$ & 1776.6 & 243.4 & 5.7 \\
\hline Tranquilizers & & $2834-1441$ & 1764.1 & 772.9 & 7.3 \\
\hline Major tranquilizers & & 2834-14411 & 383.0 & 148.2 & 151.1 \\
\hline Minor tranquilizers & & 2834-14412 & 3172.4 & 1180.2 & 0 \\
\hline Antidepressants & & $2834-1442$ & 214.3 & 3.4 & 0 \\
\hline Sedatives & & $2834-145$ & 835.5 & 10.9 & 0.8 \\
\hline Tuberculosis therapy & & $2834-147$ & 319.8 & 0 & 0 \\
\hline Vitamins & & $2834-148$ & 240.1 & 2.4 & -0.2 \\
\hline B-complex & & 2834-14829 & 302.1 & 3.0 & 1.8 \\
\hline Other vitamins & & 2834-14839 & 164.4 & 2.0 & -1.1 \\
\hline \multicolumn{6}{|l|}{ Miscellaneous prescription pharmaceutical } \\
\hline preparations & & 2834-198 & 288.7 & 2.6 & 0 \\
\hline Pharmaceutical preparations, nonprescriptions & & $2834-2$ & 197.9 & 0.4 & 0.1 \\
\hline Analgesics, internal (except antiarthritics) & & $2834-201$ & 215.8 & 0.5 & 0 \\
\hline Aspirin/aspirin-salicylate compounds & & $2834-20101$ & 295.9 & 0.8 & \\
\hline Antacids & & 2834-202 & 195.3 & 0 & 0 \\
\hline Cough and cold preparations & & $2834-208$ & 242.3 & 0.9 & 0.1 \\
\hline \multicolumn{6}{|l|}{ Cough syrups, elixirs, expectorants, drops, } \\
\hline lozenges, gums, troches & & $2834-20819$ & 194.4 & 1.0 & 0.5 \\
\hline \multicolumn{6}{|l|}{ Cold tablets, capsules (including } \\
\hline antihistamine cold preparations) & & $2834-20831$ & 292.8 & 1.0 & 0 \\
\hline Decongestants & & $2834-20849$ & 283.9 & 0.4 & 0 \\
\hline \multicolumn{6}{|l|}{$\begin{array}{l}\text { Other cough and cold preparations, } \\
\text { including decongestant and antihistamine }\end{array}$} \\
\hline mixtures & & $2834-20851$ & 223.7 & 1.0 & 0 \\
\hline Dermatologicals & & $2834-209$ & 198.6 & 3.1 & 0 \\
\hline Other dermatologicals & & 2834-20909 & 246.5 & 4.4 & \\
\hline
\end{tabular}


External analgesics and counterirritants

Laxatives

Nutrients and supplements

Ophthalmic preparations

Vitamins

Adult multivitamins

B-complex

Other vitamins

Miscellaneous nonprescription

Secondary products and miscellaneous receipts Miscellaneous receipts

Resales

Secondary products

Cosmetics and toiletries

In vivo and in vitro diagnostics

Primary products

In vitro diagnostic substances

Clinical chemistry products

Reagents

Standards and controls

Blood bank products

Hematology products

Microbiology, serology, histology, virology, and cytology products

Culture media

Other in vitro diagnostics, including coagulation products

In vivo diagnostic substances

Contrast media (X-ray media)

All other contrast media receipts pharmaceutical preparations
2834-211

2834-216

2834-217

2834-218

2834-221

2834-22101

2834-22102

2834-22109

2834-298

2934-SM

2834-M

2834-Z89

2834-S

2844-S

2835

2835-P

2835-1

2935-1A

2835-111

$2835-115$

2835-121

$2835-125$

2835-135

2835-141

2835-199

$2835-2$

2835-2A

2835-215
119.4

192.8
0 


\begin{tabular}{|c|c|c|c|c|c|}
\hline \multirow[b]{2}{*}{ Industry and Product } & \multirow{2}{*}{$\begin{array}{l}\text { Industry } \\
\text { Code }\end{array}$} & \multirow{2}{*}{$\begin{array}{l}\text { Product } \\
\text { Code }\end{array}$} & \multirow{2}{*}{$\begin{array}{l}\text { Index, } \\
\text { July } 1998\end{array}$} & \multicolumn{2}{|c|}{$\begin{array}{l}\text { Percent Change to July } 1998 \\
\text { from }\end{array}$} \\
\hline & & & & July 1997 & June 1998 \\
\hline Secondary products and miscellaneous receipts & & 2835-SM & & & \\
\hline Miscellaneous receipts & & $2835-\mathrm{M}$ & 241.2 & 10.4 & \\
\hline Resales & & $2835-Z 89$ & 138.1 & 10.5 & \\
\hline Secondary products & & $2835-\mathrm{S}$ & 228.4 & 20.7 & 0 \\
\hline Biological products, except diagnostics & 2836 & & 114.9 & 1.4 & 0.9 \\
\hline Primary products & & 2836-P & 113.5 & 1.5 & 1.0 \\
\hline Blood and blood derivatives, for human use & & $2836-1$ & 135.0 & 6.4 & 3.1 \\
\hline \multicolumn{6}{|l|}{ Other blood and blood derivatives, except } \\
\hline those used for passive immunization & & $2836-121$ & 119.8 & 6.5 & 3.2 \\
\hline Other biologics for human use & & $2836-3$ & 146.1 & -0.9 & 0 \\
\hline \multicolumn{6}{|l|}{ Allergenic extracts for human use, excluding } \\
\hline diagnostic allergens & & $2836-321$ & 310.9 & -0.9 & 0 \\
\hline \multicolumn{6}{|l|}{ Biologics for veterinary, industrial and other } \\
\hline uses & & $2836-411$ & 98.0 & -1.3 & -0.3 \\
\hline Veterinary vaccines & & $2836-411$ & 120.5 & -1.2 & -0.6 \\
\hline \multicolumn{6}{|l|}{$\begin{array}{l}\text { Other biologics including antitoxins, immune } \\
\text { serums, blood, and allergens, except }\end{array}$} \\
\hline diagnostics & & $2836-499$ & & & \\
\hline Secondary products and miscellaneous receipts & & 2836-SM & & & \\
\hline Secondary products & & $2836-\mathrm{S}$ & 121.6 & -3.9 & -0.2 \\
\hline Pharmaceutical preparations & & 2834-S & 126.0 & -4.2 & \\
\hline \multicolumn{6}{|l|}{ Secondary products except pharmaceutical } \\
\hline preparations & & 2836-SSS & 100 & -2.8 & 0 \\
\hline
\end{tabular}

Source: U.S. Department of Labor, Bureau of Labor Statistics, PPI detailed report for July 1998. 


\section{References}

American Medical Association. 1996. Physician market place 1996. Chicago, Ill.: American Medical Association.

Archibald, R. 1977. On the theory of industrial price measurement: Output price indexes. Annals of Economic and Social Measurement 6 (1): 57-72.

Berndt, E., Z. Griliches, and J. Rosett. 1993. Auditing the Producer Price Index: Micro evidence from prescription pharmaceutical preparations. Journal of Business and Economic Statistics, 11:25-63.

Catron, B., and B. Murphy. 1996. Hospital price inflation: What does the new PPI tell us? Monthly Labor Review, 119 (7): 24-31.

Diewert, W. E. 1983. The theory of output price index and the measurement of real output change. In Price level measurement, ed. W. E. Diewert and C. Montmarquette, 1049-1113. Ottawa: Statistics Canada.

Fisher, F., and K. Shell. 1972. The economic theory of price indexes. New York: Academic.

Fixler, D., and T. Jaditz. 1997. Hedonic adjustment of hospital services price inflation: An application to Medicare prices. BLS Working Paper no. 299. Washington, D.C.: Bureau of Labor Statistics.

Fixler, D., and K. Zieschang. 1992. Incorporating ancillary measures of process and quality change into a superlative productivity index. Journal of Productivity Analysis 2: 245-67.

Grabowksi, H. G., and J. Vernon. 1994. Returns to R\&D on new drug introductions in the 1980s. Journal of Health Economics 13: 383-406.

Griliches, Z., and I. Cockburn. 1995. Generics and the Producer Price Index for pharmaceuticals. In Competitive strategies in the pharmaceutical industry ed. R. B. Helms. Washington, D.C.: AEI Press.

Jacobs, P. 1974. A survey of the economic models of hospitals. Inquiry 11 (June) 83-87.

Kanoza, D. 1996. Supplemental sampling in the PPI pharmaceuticals index. Producer Price Indexes, January.

Kelly, G. 1997. Improving the PPI sample for prescription pharmaceuticals. Monthly Labor Review 120 (October): 10-17.

Levit, K. R., A. L. Sensenig, C. A. Cowan, H. C. Lazenby, P. A. McDonnell, D. K. Won, L. Sivarajan, J. M. Miller, C. S. Donham, and M. S. Stewart. 1994. National health expenditures, 1993. Health Care Financing Review 16 (1): 47.

Needham, D. 1978. The economics of industrial structure conduct and performance. New York: St. Martin's.

Newhouse, J. P. 1970. Toward a theory of nonprofit institutions: An economic model of a hospital. American Economic Review 60: 64-74.

Noether, M. 1988. Competition among hospitals. Journal of Health Economics 7: $259-84$.

Pakes, A. 1997. New goods, characteristic based models, and the role of hedonics. Yale University Department of Economics, mimeo.

Pharmaceutical Research and Manufacturers of America (PhRMA). 1997. Industry profile. Washington, D.C.: PhRMA.

Register, C. A., and E. R. Bruning. 1987. Profit incentives and technical efficiency in the production of hospital care. Southern Economic Journal 53: 899-914.

Weisbrod, B. A. 1975. Toward a theory of the voluntary non-profit sector in a three sector economy. In Altruism, morality and economic theory, ed. Edmund Phelps. New York: Russell Sage Foundation. 


\section{Comment Joseph P. Newhouse}

I applaud these authors for providing an accessible but detailed description of the PPI.

The PPI is currently used in the GDP deflator. In addition, it is better suited to a health sector deflator than the CPI because it includes government programs and employer payments in both pricing and weights, thereby picking up any cost shifting.

Nonetheless, the PPI is still subject to large potential errors for the purpose of being a health sector deflator. These are mainly covered in the Berndt, Busch, and Frank paper (Chap. 12 in this volume), but I will talk about two here. First, in principle the PPI includes quality adjustments, and the hospital, physician, and drug sections of the paper acknowledge that such adjustments are important. Nonetheless, such adjustments in fact are rarely made because there is no accepted methodology that could easily be implemented to make them.

Although I am certainly sympathetic to the practical difficulties of adjusting for quality, it is important to get some sense of how large the bias might be from rarely adjusting. The results of the Cutler et al. heart attack paper (chap. 8 in this volume) suggest that the bias from the decrease in mortality alone could be on the order of 3-4 percentage points per year. But much of medical advance does not much affect mortality so we need a method to adjust for changes in quality of life; for example, better intraocular lenses for cataracts, drug rather than surgical treatment of ulcers, human growth hormone, noninvasive imaging, kidney transplants rather than dialysis, treatments for benign prostatic hypertrophy, better hearing aids, computerized drug entry to reduce adverse drug events, Rogaine, and even Viagra.

Second, it is hard to maintain the assumption of technical efficiency within hospital and physician sectors. Almost every study of care shows substantial amounts of off-frontier care, both in the United States and elsewhere in the world (Chassin et al. 1987, 1998; Brook 1993). This means potential moves toward the frontier, including not delivering services at all or delivering a much lower priced placebo (watchful waiting) are not valued in the index.

I have three nuts-and-bolts type comments. I would have liked more material on the adequacy of the sample. The paper gives numbers on attrition, but there is no effort to assess bias or variance. The paper notes that 21 percent of hospital quotes are of the DRG type, but Medicare alone accounts for 16 percent of discharges ( 33 percent of the dollars), and about

Joseph P. Newhouse is the John D. MacArthur Professor of Health Policy and Management and is on the faculties of the Kennedy School of Government, the Harvard Medical School, the Harvard School of Public Health, and the Faculty of Arts and Sciences at Harvard University, and is a research associate of the National Bureau of Economic Research. 
half the state Medicaid programs use DRGs as do some private payers. So this value seems low. Second, the exclusion of Puerto Rico in the drug area may create a bias. I'm not clear about the arguments for not changing this policy, but it would be nice to have a sense of how large the bias could be. Finally, about 15 percent of the population is uninsured. These people generally receive some form of charity care. In principle, the actual price received by the hospital or physician is tracked, but I am unclear as to how often this happens. This would seem to be a particular problem with government hospitals that receive an appropriation to cover care.

\section{References}

Brook, Robert H. 1993. Maintaining hospital quality: The need for international cooperation. Journal of the American Medical Association 270 (8): 985-87.

Chassin, Mark, et al. 1987. Does inappropriate use explain geographic variations in the use of health care services? A study of three procedures. Journal of the American Medical Association 258 (18): 2533-37.

Chassin, Mark R., Robert W. Galvin, and the National Roundtable on Health Care Quality. 1998. The urgent need to improve health care quality. Journal of the American Medical Association 280 (11): 1000-5. 
This Page Intentionally Left Blank 